DOE/ER83809-1

\title{
DEVELOPMENT OF PROTECTIVE COATINGS FOR SINGLE CRYSTAL TURBINE BLADES
}

\author{
Final Report
}

For Period July 212003 - April 202004

Amarendra K. Rai

UES, Inc.

4401 Dayton-Xenia Road

Dayton, OH 45432-1894

December 2006

Prepared for

THE U.S. DEPARTMENT OF ENERGY

Contract No. DE-FG02-03ER83809

\begin{abstract}
NOTICE
This report was prepared as an account of work sponsored by the United States Government. Neither the United States Department of Energy, nor any of their employees, nor any of their awardees, subcontractors, or their employees, makes any warranty express or implied, or assumes any legal liability or responsibility for the accuracy, completeness, or usefulness of any information, apparatus, product or process disclosed or represents that its use would not infringe privately-owned rights.
\end{abstract}




\section{FOREWARD}

This document is a final report covering work performed under Contract No. DE-FG0203ER83809 from the Department of Energy under a Small Business Innovative Research (SBIR) Phase I Program. The research covered in this report was performed by the Materials Laboratory at UES, Inc. New Mexico Institute of Mining and Technology was a subcontractor on this project (Dr. Bhaskar Majumdar). Besides the principal investigator the author of this report, Dr. Amarendra K. Rai, other key UES personnel who were actively involved in this project include: Dr. Satish Dixit, Dr. Rabi Bhattacharya, and Mr. Boris Brodkin. Ms. Jan Clark of UES has provided excellent administrative support throughout this Phase I Project. 


\subsection{INTRODUCTION}

The U.S. Department of Energy (DOE) has as its mission to foster the development and deployment of advanced, clean, and affordable fossil-based (coal) power systems. The efficiency of these systems mainly depends on the performance of the turbine section. The turbine blades, which are the integral part of the system, are made of polycrystalline, directionally solidified or single crystal Ni-based superalloys. The turbine blade, in the generator, experiences a very hostile environment. The steam temperatures in the Turbine section can range from $1000^{\circ} \mathrm{F}$ to $1300^{\circ} \mathrm{F}\left(537^{\circ} \mathrm{C}-704^{\circ} \mathrm{C}\right)$ and it is injected at a pressure between 1800 to 3500 pounds per square inch. This could have very deleterious effects on the metallurgy and chemistry of the blades. The hot steam injected at high velocities could lead to high corrosive and erosive damage to the blades. This in turn leads to lower turbine section efficiencies and thereby reduced overall performance of the power plant itself. The road to higher efficiency is higher turbine Rotor Inlet Temperature (RIT). Increasing temperatures beyond $2350^{\circ} \mathrm{F}\left(1288^{\circ} \mathrm{C}\right)$ used in today's systems represents a significant challenge to materials science.

A solution to this problem is the use of Thermal Barrier Coatings (TBCs). TBCs have been used for almost three decades to extend the life of gas and land based turbine engine components. TBCs protect the underlying base metal by removing the lower melting point base material from high heat flux/temperature regions. In the following paragraphs we will discuss the advantages of TBC and their limitations.

The advantages of thermal barrier coatings (TBCs) in hot-section turbine components are best illustrated by Figure 1 .

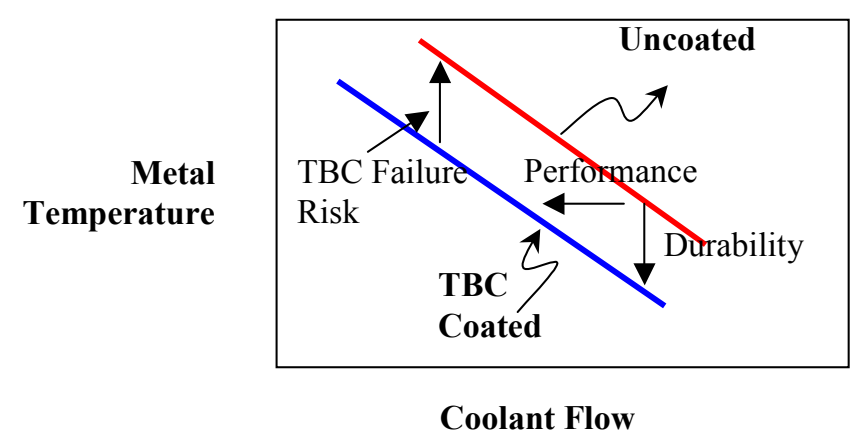

Figure 1. Sketch illustrating the advantages of a thermal barrier system, and the risk associated with failure of the TBC.

(i) At constant coolant flow, they reduce the base metal temperature, thereby increasing the life of that part. Advanced turbine blades in land based generators and aerospace engines operate very close to their melting temperature, and it is estimated that a $30-60^{\circ} \mathrm{F}$ reduction in metal temperature can produce a two-fold increase in life [1-3].

(ii) At existing metal temperature, the temperature at the TBC surface can be increased by as much as $150^{\circ} \mathrm{F}$, leading to a substantial gain in fuel efficiency. It is estimated that this temperature advantage is equivalent to two generations of new superalloy development [1-3]. 
These advantages constitute immense cost savings to both the aerospace and land based gas turbine generators. Unfortunately, the above benefits of TBCs have not been realized in practice. This is largely because the performance of even the advanced TBCs is not considered prime-reliant or sufficiently reliable and predictable [4]. In addition, the life of these TBCs needs significant improvement.

Thus, there is a need to develop TBC systems that have significantly higher reliability and durability than current state-of-the-art systems. In order to appreciate the problems associated with current TBCs, and also to provide a basis for our Phase I approach to the problem, it is important to understand the failure mechanisms of TBCs.

As shown in Figure 2, state-of-the-art TBCs comprise: (1) a ductile metallic bond coat that is deposited on the structural member (e.g., a superalloy turbine blade) to provide an added level of oxidation protection to the superalloy, (2) an outer layer of highly compliant (low stiffness) yttria stabilized zirconia (YSZ) of low thermal conductivity, which allows the superalloy to operate at a lower temperature than the surroundings, resulting in longer life, and, (3) a thermally grown oxide (TGO) layer, that grows as a result of oxygen diffusion through the YSZ layer to the bond coat surface.

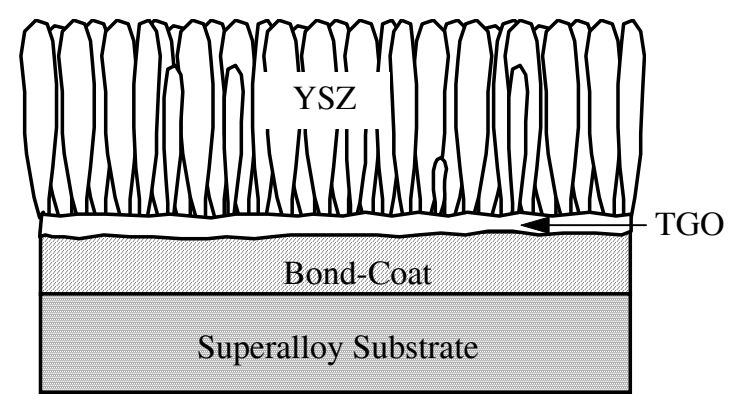

Figure 2. Sketch illustrating the principle components of a TBC system.

Current bond coats are either based on NiCoCrAlY or Pt-Al material systems, and are usually 70-100 $\mu \mathrm{m}$ thick. The former is usually deposited using a plasma spray process, whereas the latter is applied by first electrolytically depositing Pt on the superalloy, followed by pack cementation with A1. The YSZ is typically of $100 \mu \mathrm{m}$ thickness and is mostly deposited using an electron beam physical vapor deposition (EB PVD) technique, since it provides a columnar and highly compliant layer. Thereby the YSZ layer cannot accumulate too much stress/strain energy that would drive YSZ delamination. In some cases YSZ layer is also deposited by plasma spray. It should be mentioned that the durability of EB PVD YSZ is ten times better than that deposited by plasma spray [5].

The most important component of the TBC is, however, the TGO. As shown in Figure 3, the growth of this TGO layer is generally thought to occur by the inward diffusion of $\mathrm{O}^{-2}$ ions through the TGO layer, followed by additional oxidation of the bond coat. 


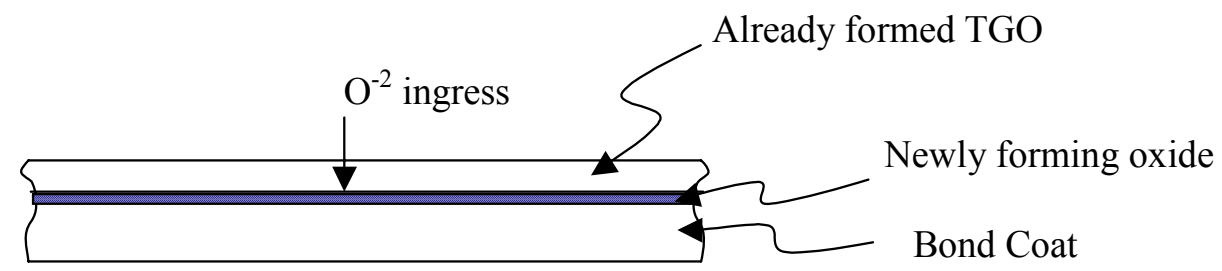

Figure 3. Sketch illustrating continued growth of the TGO.

Damage and final spallation of the YSZ is primarily due to growth of the TGO layer, which can have very large compressive stresses ( $2-4 \mathrm{GPa}$ ) when cooled to RT, because of large thermal expansion mismatch between the oxide and the bond coat [6]. Since the strain energy in the TGO is proportional to the thickness of the TGO, the driving force for delamination, primarily through TGO buckling, increases as the TGO thickness increases. In addition, the growth of the TGO is associated with rumpling of the bond coat/TGO interface, which greatly aids buckling and delamination of the TGO+YSZ (see Figure 4).

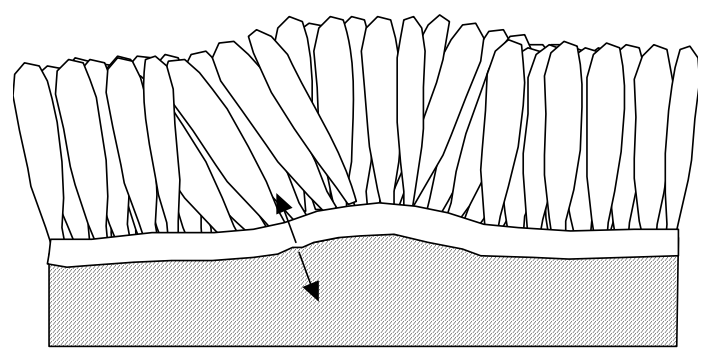

Figure 4. Surface rumpling caused by oxidation, or due to surface irregularities on the bond coat, can cause tensile stresses (see arrows) to be generated at the bond coat/TGO interface. This can initiate and propagate delamination failure of the TGO. The magnitude of these stresses scale with TGO thickness, and hence reduced growth of TGO is important to retain TBC integrity.

Experiments also show that TGO growth and ultimate coating delamination are greatly enhanced under thermal cycling conditions compared to isothermal oxidation conditions. That is why thermal cycling experiments provide more realistic understanding of TBC performance in service.

A number of mechanisms have been suggested for the surface rumpling. For example, one proposed mechanism [7] is that the depletion of metallic elements (primarily Al) by oxidation must necessarily be accompanied with shrinkage of the bond coat. Since the bond coat is constrained by the superalloy substrate, the bond coat can shrink only in the thickness direction. This by itself may not be greatly detrimental. However, should the shrinkage be nonuniform because of unequal supply of elements from different phases, then a wavy rumpled surface would necessarily result. Results of some of our previous work on TBCs [8] as well as those reported in [7], attest to this mechanism. Other mechanisms have also been proposed as well [6]. The more significant point is that TGO growth is detrimental to TBC durability, so that efforts to increase TBC life must emphasize methods that can reduce the growth rate of the TGO. In this regard, note that although $\alpha$-alumina is found to be the primary constituent of the TGO, 
other oxides and spinels are also observed. These oxides are not as protective as the $\alpha$-alumina layer, create defects in the TGO layer, and are generally fast growing. One method to reduce their growth significantly is to generate low partial pressure conditions, such that $\alpha-\mathrm{Al}_{2} \mathrm{O}_{3}$ growth is favored over any mixed oxide (Ellingham diagram). An initial highly perfect $\alpha-\mathrm{Al}_{2} \mathrm{O}_{3}$ layer would create such conditions, and thereby not only ascertain a reduced oxidation rate, but also assure a more adherent and defect free $\alpha$-alumina film. The overall effect would be a reduced rate of growth of the TGO. In other words, if TGO growth could be reduced, then a significantly improved life of the TBC would be possible. The Phase I work attempted to solve the problem using either a high quality alpha-alumina or a YAG sublayer.

In Phase I work, our approach to develop an improved TBC system was to reduce the TGO growth. This was achieved by first depositing a highly smooth and defect (pore) free bond coat on single crystal superalloy (CMSX-4) using UES' large area filtered cathodic arc deposition (LAFAD) process, and then a alpha alumina $\left(\alpha-\mathrm{Al}_{2} \mathrm{O}_{3}\right)$ or a yttrium aluminum garnet (YAG) layer on top of the bond coat using an arc-enhanced sputtering process. Finally, a standard EB-PVD YSZ layer was deposited on alumina or YAG layer.

One of the important requirements of the bond coat is to have very good oxidation resistance for maximum protection to the substrate. Thus, an alloy composition that promotes alumina (TGO) formation with enhanced adhesion to the substrate is preferred. The standard bond coats used in the industry are NiCoCrAlY and Pt-Ni-Al. Recently it has been shown by Wright et al. that a bond coat with a composition of Ni-20Cr-19Al-Y (no Co) provides better oxidation life than the standard NiCoCrAlY coating [9]. This could be related to better adhesion of TGO with this (NiCrAlY) bond coat. In the industry, NiCoCrAlY is deposited by plasma spray and Pt-Ni-Al is deposited by first electrodepositing Pt onto the superalloy component and then annealing it in an aluminum rich vapor atmosphere. This allows diffusion of aluminum in to the surface of the alloy while Ni diffuses out where it reacts with the Al and Pt to form the Pt-NiAl coating. The coatings produced by both of these techniques are very rough, and the plasma spray coating, in particular, is very porous. Thus, our approach was to use the relatively novel LAFAD technique to produce the bond coat. As explained later, this technique has the ability to generate a "plasma immersion" environment using powerful arc plasma sources and auxiliary anodes to provide highly ionized plasma surrounding the part. This process provides high plasma ionization $(>90 \%)$ compared to standard PVD processes $(>20 \%)$. The multiply charged ions provide high reactivity of the plasma, thereby allowing very good bonding to the substrate.

The rationale for depositing $\alpha-\mathrm{Al}_{2} \mathrm{O}_{3}$ or YAG layer on top of the bond coat is that both of these materials have very low oxygen diffusivity (see Table 1). The thermodynamically stable $\alpha$ $\mathrm{Al}_{2} \mathrm{O}_{3}$ or YAG with minimal defects (unlike TGO) will be highly resistant to the inward diffusion of oxygen. This will significantly reduce the rate of oxidation below the deposited alumina or YAG layer. 
Table 1. Physical Properties of TBC Components

\begin{tabular}{|l|l|l|l|l|}
\hline \multicolumn{1}{|c|}{ Properties } & \multicolumn{1}{|c|}{$\mathrm{Y}_{3} \mathrm{Al}_{5} \mathrm{O}_{12}(\mathrm{YAG})$} & \multicolumn{1}{|c|}{$\alpha-\mathrm{Al}_{2} \mathrm{O}_{3}$} & \multicolumn{1}{c|}{ YSZ } & NiCoCrAlY \\
\hline Crystal & cubic & hexagonal & tetragonal & \\
\hline Density $\left(\mathrm{g} / \mathrm{cm}^{3}\right)$ & 4.55 & 3.98 & $5.0-6.0$ & \\
\hline Melting Temp. $\left({ }^{\circ} \mathrm{C}\right)$ & 1970 & 2045 & 2700 & \\
\hline $\begin{array}{l}\text { Thermal conductivity }(\mathrm{k}) \\
(\mathrm{w} / \mathrm{m} . \mathrm{k})\end{array}$ & $8.8(298 \mathrm{~K})$ & 46 & $3.1(373 \mathrm{~K})$ & 11 \\
\hline $\begin{array}{l}\text { Coeff. of thermal } \\
\text { expansion }\left(\mathrm{x} 10-6 /{ }^{\circ} \mathrm{C}\right)\end{array}$ & $3.6(1000 \mathrm{~K})$ & 10 & $2.6(873 \mathrm{~K})$ & \\
\hline Youngs Modulus $(\mathrm{E})(\mathrm{GPa})$ & 335 & 7 & 10 & 13 \\
\hline Hardness $(\mathrm{GPa})$ & $17-19$ & & 294 & \\
\hline $\begin{array}{l}\text { Coeff. of diffusion } \\
(\mathrm{cm} / \mathrm{sec}) \text { at } 1373 \mathrm{~K}\end{array}$ & $\mathrm{D}^{\mathrm{o}}{ }_{\mathrm{v}} \sim 10^{-16}$ & 20 & 13 & 200 \\
& $\mathrm{D}^{\mathrm{o}}{ }_{\mathrm{gb}} \sim 10^{-12-13}$ & $\mathrm{D}^{\mathrm{o}}{ }_{\mathrm{v}} \sim 10^{-16}$ & $\mathrm{D}^{\mathrm{o}}{ }_{\mathrm{v}} \sim 10^{-10-11}$ & \\
& $\mathrm{D}^{\mathrm{Y}}{ }_{\mathrm{v}} \sim 10^{-18} \sim 10^{-10-11}$ & & \\
& $\mathrm{D}^{\mathrm{Al}}{ }_{\mathrm{v}} \sim 10^{-17}$ & $\mathrm{D}_{\mathrm{v}} \sim 10^{-15}$ & & \\
\hline
\end{tabular}

The $\alpha-\mathrm{Al}_{2} \mathrm{O}_{3}$ layer can also act as a seed for growth of new alumina, which must grow below the deposited $\alpha-\mathrm{Al}_{2} \mathrm{O}_{3}$ layer (i.e., toward the bond coat side of the TGO). The low partial pressure of oxygen below the $\alpha-\mathrm{Al}_{2} \mathrm{O}_{3}$ will aid this seeding process, and reduce the formation of other mixed oxides and spinels. This type of seeding has been suggested by $\mathrm{Su}$, et al. [10], where they conducted oxidation tests on a Rene N5 superalloy with and without an $\alpha-\mathrm{Al}_{2} \mathrm{O}_{3}$ layer $\left(\sim 0.15 \mu \mathrm{m}\right.$ thick); no bond coat was utilized in their study. A CVD templated $\alpha-\mathrm{Al}_{2} \mathrm{O}_{3}$ layer exhibited only $0.7 \mu \mathrm{m}$ of new TGO formation on isothermal exposure at $1150^{\circ} \mathrm{C}$ for 500 hours. In the absence of the $\alpha-\mathrm{Al}_{2} \mathrm{O}_{3}$ layer, the TGO spalled and the system exhibited weight loss characteristics [10]. One improvement to this approach is the incorporation of less than 1 weight percent $Y$, since the presence of $Y$ has been found to reduce the grain boundary diffusion of oxygen in alpha alumina by more than one order of magnitude [11]. A lower oxygen flux would reduce alumina growth, as well as cut down the counter current of Al, which can otherwise cause Kirkendall type of porosity in the bond coat near the TGO.

YAG layer is attractive because of its interesting properties such as CTE of about 9, thermal conductivity of $3.6 \mathrm{~W} / \mathrm{m} . \mathrm{K}$ at $1000 \mathrm{~K}$, and grain boundary ( $\mathrm{gb}$ ) oxygen diffusivity $\left(\mathrm{D}_{\mathrm{gb}}\right)$ about two orders of magnitude lower than the $\alpha-\mathrm{Al}_{2} \mathrm{O}_{3}$ (Table 1). YAG possesses a cubic crystal structure (Garnet) with high melting temperature ( 1970C), and is known to be the most creep resistant oxide [12]. Unlike $\mathrm{Al}_{2} \mathrm{O}_{3}, \mathrm{YAG}$ shows no polymorphic transition and is stable up to the melting temperature. Figure 5 is a schematic depicting UES' approach for the TBC system.

In Phase I, UES demonstrated a smooth and dense NiCoCrAlY (45Ni-23Co-19Cr12.5Al-0.50Y) coating using LAFAD technique. Also in Phase I, conditions were determined for deposition of $\alpha-\mathrm{Al}_{2} \mathrm{O}_{3}$ layer on top of the bond coat. The deposition of $\alpha-\mathrm{Al}_{2} \mathrm{O}_{3}$ was confirmed using X-ray diffraction (XRD) technique. Conditions for the deposition of YAG layer were also determined. On some of these samples, EB-PVD YSZ layer was deposited at Howmet Research Center (Ken Murphy). Isothermal and cyclic oxidation tests were conducted for preliminary evaluation of the oxidation performance of the coatings and data compared with those quoted in the literature. Such studies in Phase I have demonstrated superior oxidation resistance of the proposed TBC design. 


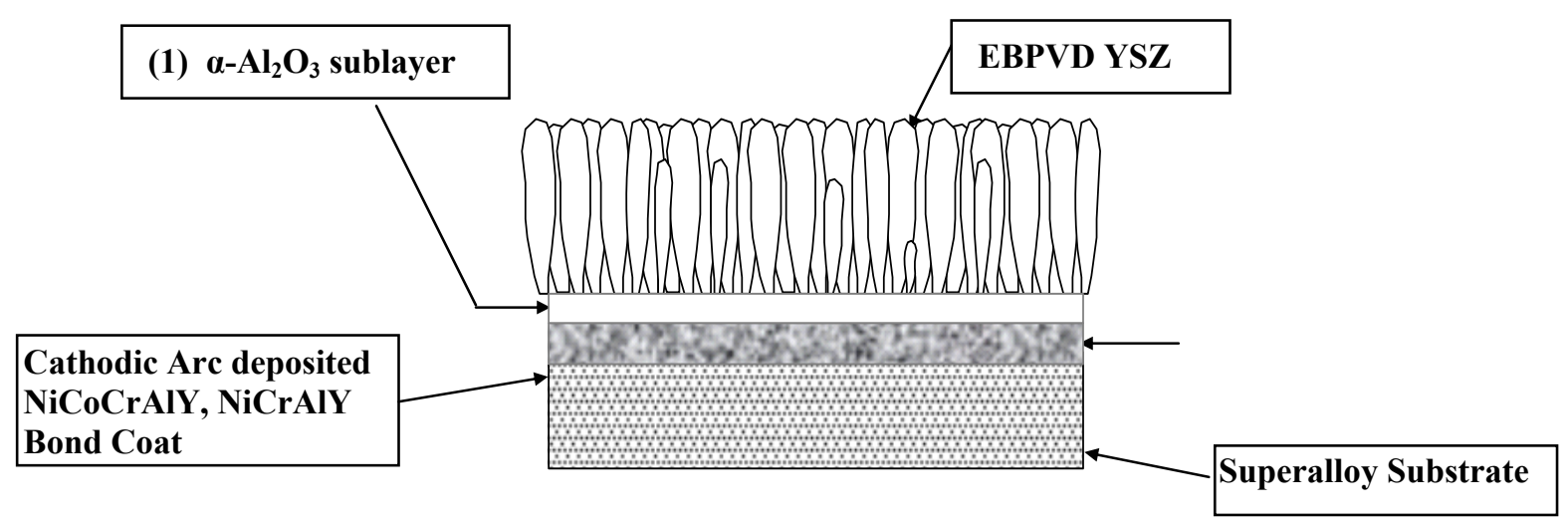

Figure 5. The UES Approach for the TBC System.

\subsection{PHASE I TECHNICAL OBJECTIVES}

The overall objective of the Phase I program was to develop a prime reliant TBC system using a unique coating design approach. The conventional coating design CMSX-4/ $\mathrm{NiCoCrAlY/YSZ} \mathrm{is} \mathrm{not} \mathrm{prime-reliant} \mathrm{or} \mathrm{sufficiently} \mathrm{reliable} \mathrm{and} \mathrm{predictable.} \mathrm{A} \mathrm{major} \mathrm{reason} \mathrm{for}$ this is conjectured to be due to low density (high porosity) and rough surface morphology of the bond coat (NiCoCrAlY). This leads to uneven oxidation of the bond coat. Thus for reliable and predictable TBC system the surface roughness and the uneven oxidation of the bond coat has to be minimized. The research carried out in Phase I was focused on the development of smoother NiCoCrAlY surface and prevention of uneven oxidation of the bond coat. This was carried out by the filtered cathodic arc deposition of the bond coat and by depositing a $\alpha-\mathrm{Al}_{2} \mathrm{O}_{3}$ or YAG layer on top of the bond coat. In Phase I, the potential of such approach was demonstrated by conducting the cyclic oxidation test on the coated coupons.

\subsection{PHASE I RESULTS}

\section{Coating Deposition System}

The deposition of the bond coat and $\alpha-\mathrm{Al}_{2} \mathrm{O}_{3}$ (or YAG) was accomplished by utilizing large area filtered arc deposition (LAFAD) system shown schematically in Figure 6. The LAFAD system consists of a rectangular chamber with two large area filtered arc sources and deflecting magnetic coil assembly, and a cylindrical deposition chamber with two direct arc sources and an auxiliary anode assembly. The direct arc sources can be replaced by two magnetron sputter sources. Appropriate gases can be introduced into the deposition chamber for reactive deposition. The auxiliary anode assembly facilitates the generation of a highly ionized metal and/or gas plasma in which the substrate can be immersed. The deposition chamber has a built-in carousel type double planetary rotation system for mounting substrates. Overall the system is capable of accommodating relatively large complex shaped parts for coating deposition.

The filtered arc sources can be operated in two different modes viz., with magnetic field on or off. In the magnetic field on situation, only the ionized part of the arc metal plasma is deflected along the curvilinear magnetic field towards the substrate to obtain highly dense and 
smooth coating. In the magnetic field off mode, only the electrons (and not the metal ions) can be extracted from the filtered arc plasma into the deposition chamber to obtain a highly ionized discharge plasma of a relevant gas. In this mode sputter deposition can be done in an arc enhanced Ar plasma. These two modes of operation were used for the deposition of bond coat and either $\alpha-\mathrm{Al}_{2} \mathrm{O}_{3}$ or $\mathrm{YAG}$, respectively.

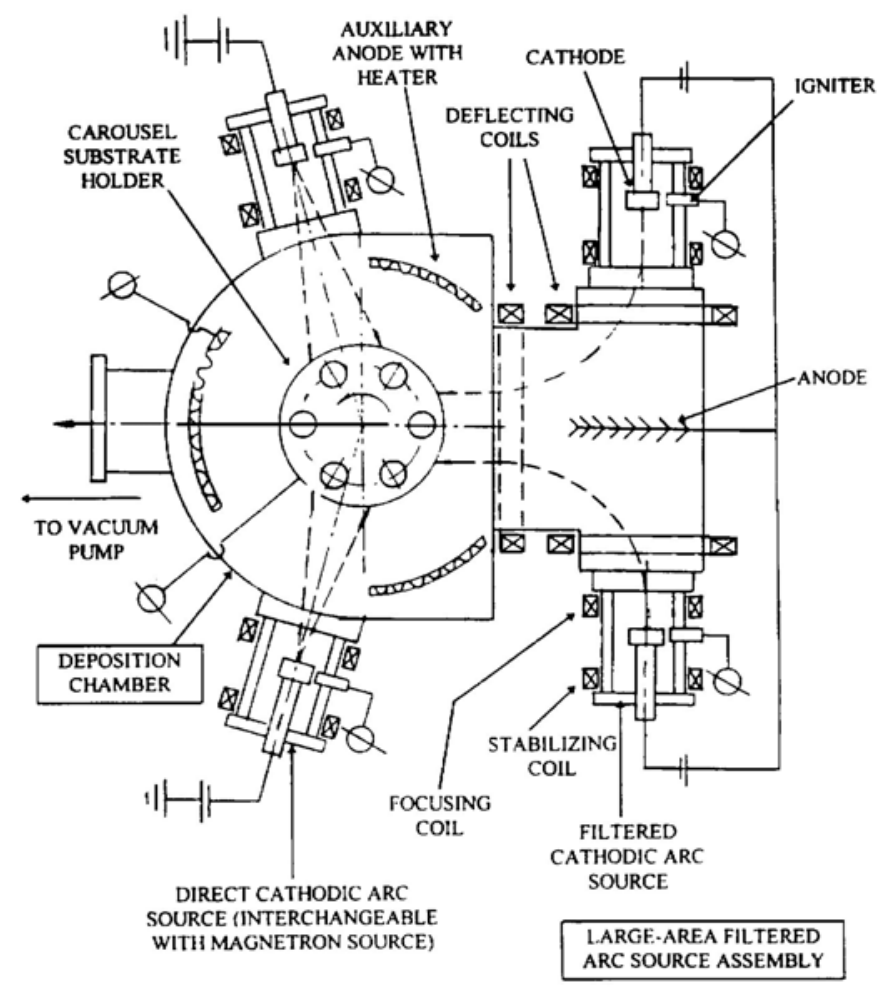

Figure 6. Schematic Diagram of the Large Area Filtered Arc Deposition System.

\section{Substrate Preparation}

Approximately 1 inch diameter discs of single crystal CMSX-4 alloy were polished to have a smooth surface finish. Final polishing was done with $1 \mu \mathrm{m}$ diamond paste. The polished discs of CMSX-4 were used as substrate coupons. The coupons were ultrasonically degreased in acetone and isopropyl alcohol. The cleaned coupons were mounted on a fixture designed to hold many coupons. The fixture was mounted on the double planetary rotation system of the Large Area Filtered Arc Deposition (LAFAD) system available at UES.

\section{Coating Deposition and Characterization}

\section{$\underline{\text { Bond Coat }}$}

A composite target comprising of nominal composition of $45 \mathrm{Ni}-23 \mathrm{Co}-19 \mathrm{Cr}-12.5 \mathrm{Al}-0.5 \mathrm{Y}$ (wt.\%) was used as filtered arc source in the LAFAD system. The deposition system was evacuated to a base pressure of $10^{-3} \mathrm{~Pa}$. Prior to the deposition of NiCoCrAlY coating the substrate coupons were sputter cleaned in Ar plasma. The coating was deposited at the substrate temperature of $400^{\circ} \mathrm{C}$ and a bias of $-60 \mathrm{~V}$. 
The surface morphology of the bond coat sample was examined in the optical microscope. Figure 7a represents an optical photograph of the surface of the filtered arc deposited bond coat (NiCoCrAlY). For comparison purpose the surface morphology of the standard bond coat deposited by plasma spray is shown in Figure $7 \mathrm{~b}$. The surface of the filtered arc deposited bond coat appeared much smoother with finer grain size than that of the standard bond coat.

Figure 8 shows a cross sectional photograph of the bond coat on CMSX-4 superalloy. Careful examination of the bond coat revealed only few defects otherwise it is fairly smooth. Also, the bond coat has essentially defect-free bonding to the substrate. In this regard, note that our observation has been that standard NiCoCrAlY and Pt-Al bond coats often contain pores/defects of sizes 5-10 micron at the bond coat/superalloy interface. Such defects can be extremely detrimental to long-term performance. The filtered arc deposition process also assures a fine grain microstructure, which can be useful to reduce surface rumpling through unequal depletion of alloying elements. The chemical composition of the NiCoCrAlY bond coat was determined by energy dispersive x-ray (EDS) analysis. An EDS spectrum of the bond coat is shown in Figure 9. Quantitative analysis of the chemical composition of the bond coat was also done and the results are shown in Table 2. For comparison purposes the nominal composition of the arc target is also given in Table 2. Except for Al, the measured concentrations of all the other elements were found to be close to the nominal composition of the target.

\section{$\underline{\text { Alpha Alumina/Bond Coat }}$}

$\alpha-\mathrm{Al}_{2} \mathrm{O}_{3}$ coating was deposited on top of the bond coat at a substrate temperature of $\sim 750^{\circ} \mathrm{C}$ by arc enhanced sputtering technique. In this technique, an alumina sputter target was placed in the large area filtered arc deposition (LAFAD) system and Al targets were installed in the filtered arc sources. Sputtering was performed in the Ar plasma. Highly ionized Ar plasma was created by operating the filtered arc sources and by directing the electrons into the deposition chamber. The coating thickness was $\sim 1-2 \mu \mathrm{m}$.

Figure 10 shows the $\mathrm{XRD}$ data of the as-deposited $\mathrm{Al}_{2} \mathrm{O}_{3}$ layer. A standard $\mathrm{X}$-ray diffractometer was used for the purpose, rather than a glancing angle XRD. Therefore, the diffraction profile contains reflections from both the alumina layer and the NiCoCrAlY layer. The latter is a two-phase structure consisting of a $\beta$ NiAl phase that is rich in Al, and a $\gamma$-Ni-alloy solid solution that contains the bulk of the heavier elements.

In Figure 10, the peaks at $2 \theta$ values of $25.8,35$, and 57.8 degrees correspond to characteristic $\alpha-\mathrm{Al}_{2} \mathrm{O}_{3}$ peaks, which are not present in either the superalloy substrate, or in the $\mathrm{NiCoCrAlY}$ coating. Some of the other peaks of $\alpha-\mathrm{Al}_{2} \mathrm{O}_{3}$, seen in XRD profiles of $\alpha-\mathrm{Al}_{2} \mathrm{O}_{3}$ powder, are either shadowed by the substrate peaks, or are greatly minimized by film texture. In previous studies [8], we have confirmed $\alpha-\mathrm{Al}_{2} \mathrm{O}_{3}$ in the layer using Rutherford Back Scattering, as well as micro-Raman technique, and those results correlated very well with the characteristic XRD peaks. These latter measurements have not yet been conducted in the Phase I work. Note also that analysis of the XRD data failed to confirm the presence of other alumina phases, notably $\kappa$ and $\gamma$ alumina. Such phases are observed if alumina deposition conditions are not correct. 


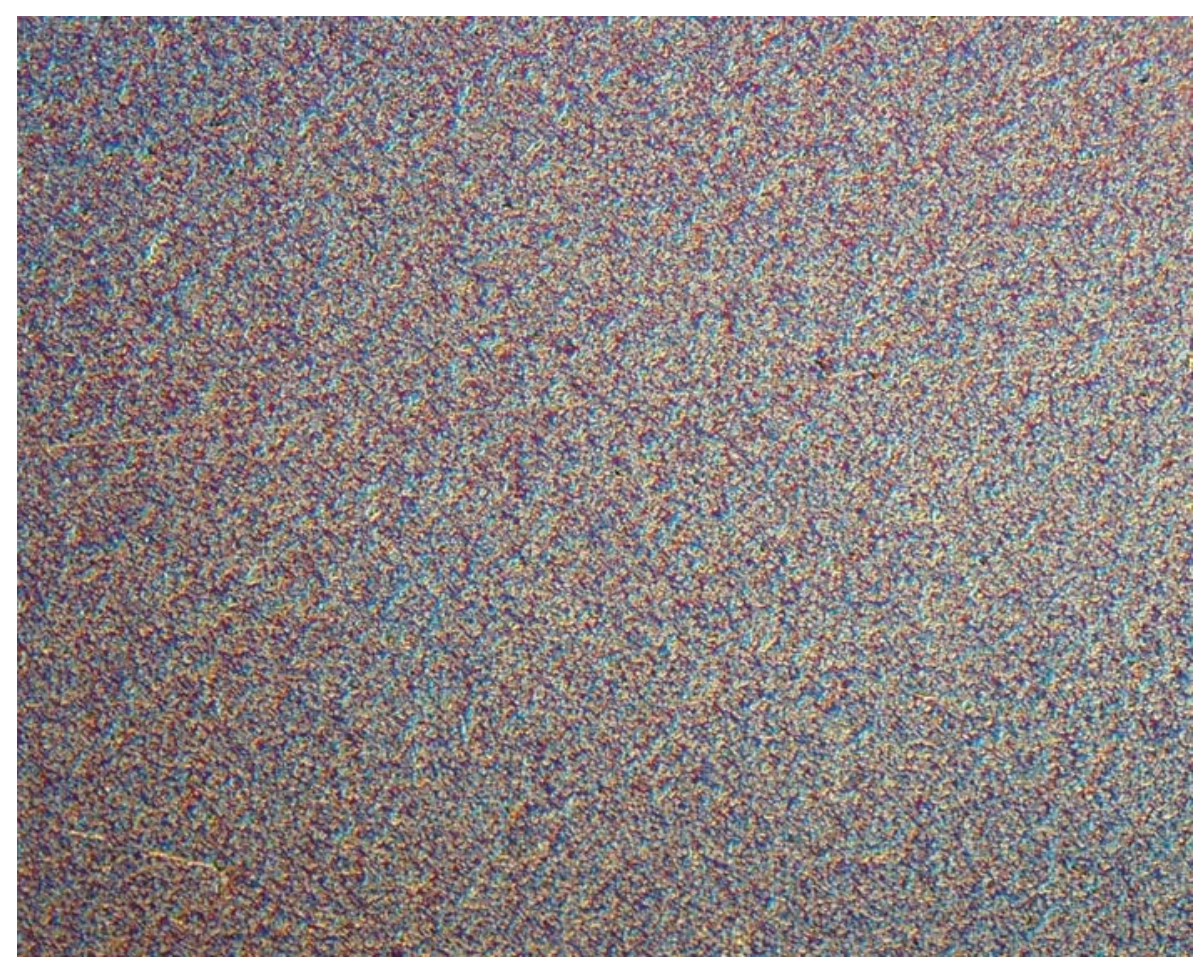

(a)

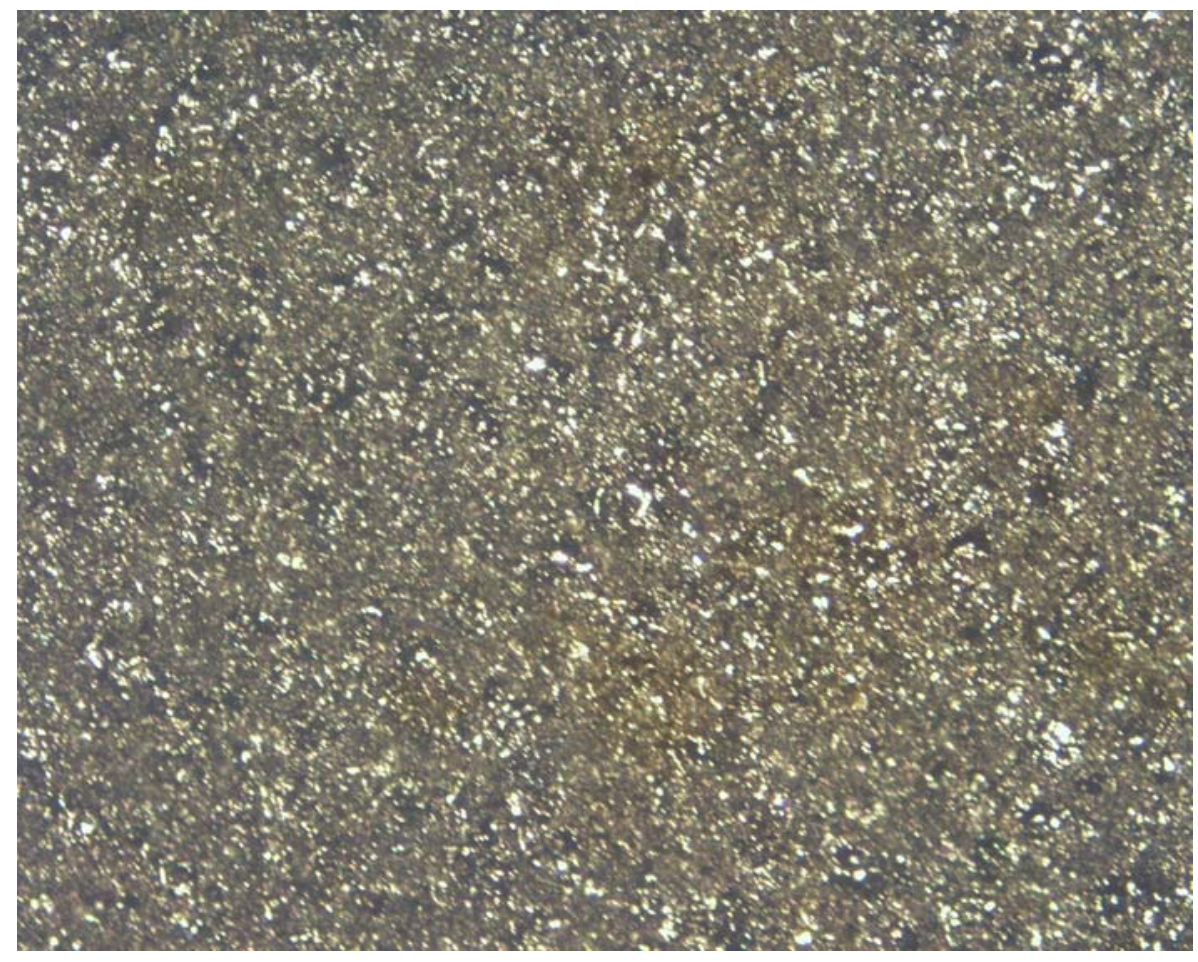

(b)

Figure 7. Optical photographs of the surface of the NiCoCrAlY bond coat deposited by (a) filtered arc, and (b) plasma spray. 


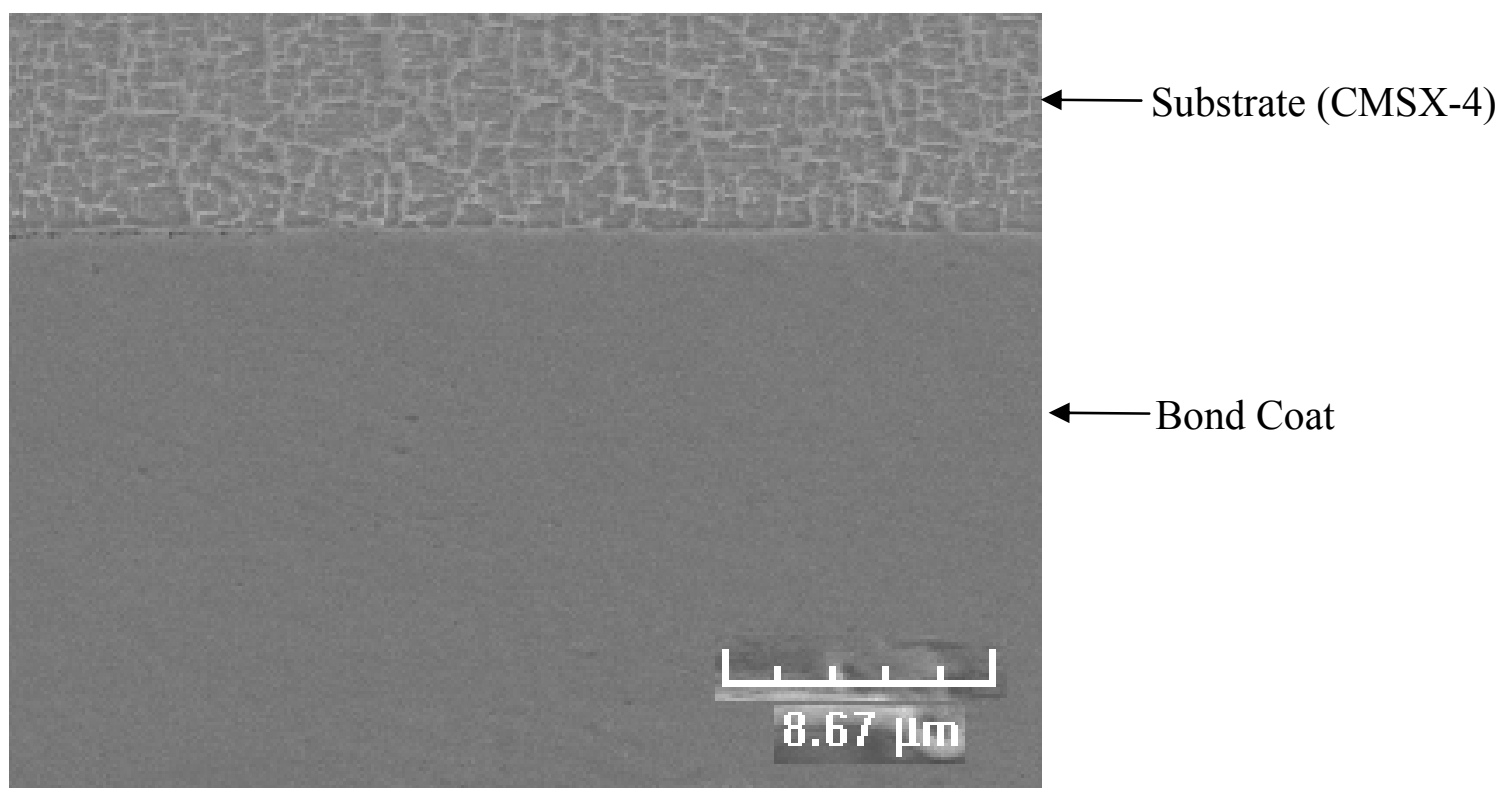

Figure 8. Cross-sectional SEM micrograph of the filtered arc deposited NiCoCrAlY bond coat on CMSX-4 substrate.

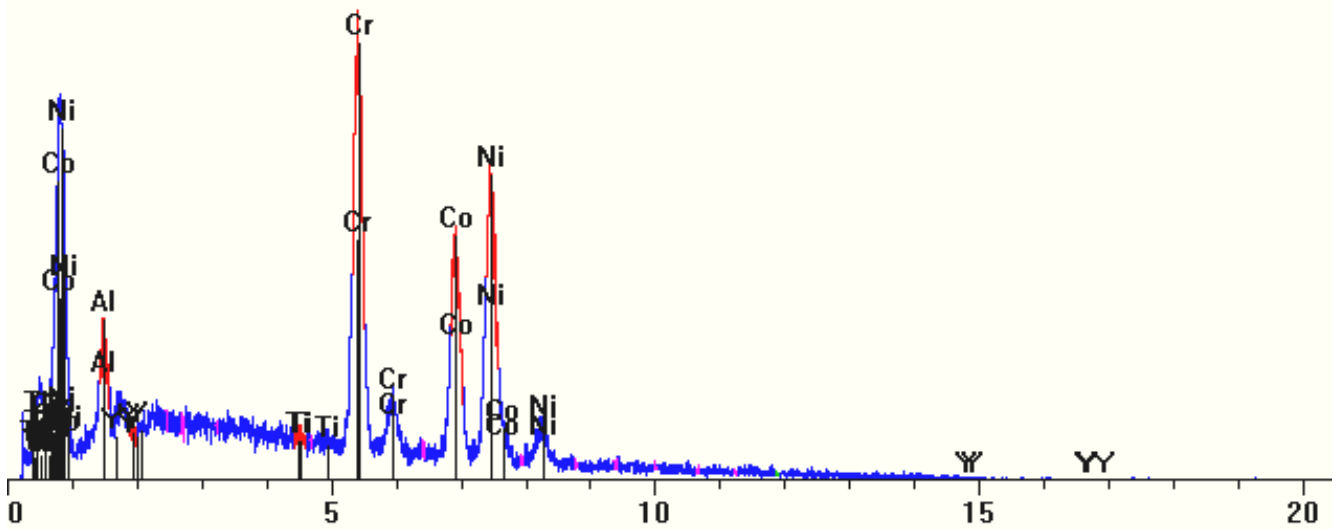

Figure 9. Energy Dispersive X-ray (EDS) Spectrum of the NiCoCrAlY Bond Coat.

Table 2. Chemical Composition of Bond Coat

\begin{tabular}{|c|c|c|c|c|c|c|}
\hline Element & Line & keV & KRatio & $\mathbf{W t \%}$ & At\% & Target (wt.\%) \\
\hline Al & KA1 & 1.487 & 0.0227 & 4.45 & 8.69 & 12.5 \\
Cr & KA1 & 5.414 & 0.2855 & 26.49 & 27.60 & 19 \\
Co & KA1 & 6.929 & 0.2572 & 26.57 & 24.43 & 23 \\
Ni & KA1 & 7.477 & 0.4177 & 42.22 & 38.98 & 45 \\
Y & LA1 & 1.922 & 0.0018 & 0.27 & 0.16 & 0.5 \\
Total & & & & $\mathbf{1 0 0 . 0 0}$ & $\mathbf{1 0 0 . 0 0}$ & $\mathbf{1 0 0 . 0 0}$ \\
\hline
\end{tabular}


X-ray Diffraction Pattern for Sample B

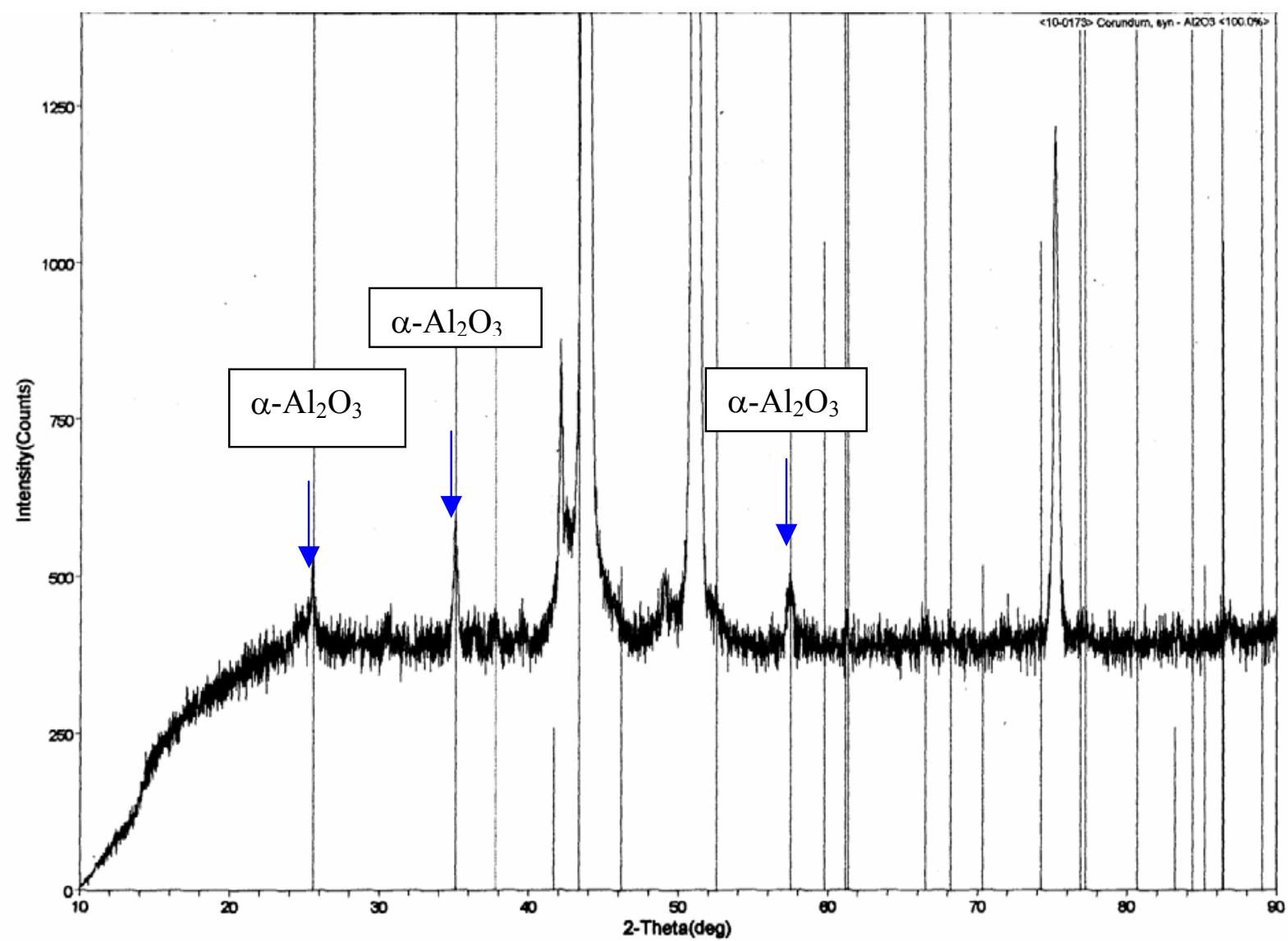

Figure 10. XRD of the alumina layer deposited on top of the cathodically deposited NiCoCrAlY bondcoat. Peaks belonging to $\alpha-\mathrm{Al}_{2} \mathrm{O}_{3}$ are indicated by the arrows. A large peak at approximately 43 degrees, (113), is hidden by the base NiCoCrAlY peak. The solid vertical lines are for $\alpha-\mathrm{Al}_{2} \mathrm{O}_{3}$.

Although additional transmission electron microscope (TEM) analysis needs to be conducted to accurately estimate the purity of the $\alpha-\mathrm{Al}_{2} \mathrm{O}_{3}$ phase, the XRD data to date do provide strong evidence for the presence of only the $\alpha-\mathrm{Al}_{2} \mathrm{O}_{3}$ phase.

Additional indirect evidence for the presence of only $\alpha-\mathrm{Al}_{2} \mathrm{O}_{3}$ can be assessed from the integrity of the coating under thermal cycling conditions, where the highest temperature is greater than $1100^{\circ} \mathrm{C}$. Only the $\alpha-\mathrm{Al}_{2} \mathrm{O}_{3}$ phase remains stable under such cycling conditions, whereas other oxides undergo volumetric contraction as large as 6 to $7 \%$. Such contractions will lead to cracking of the oxide and rapid disintegration of the film. It will be demonstrated shortly that the alumina exhibited excellent resistance to cracking under thermal cycling conditions.

Cyclic oxidation tests were performed on three different samples viz. sample D (bare substrate), sample $\mathrm{C}$ (substrate with cathodically deposited NiCoCrAlY bond coat) and sample B $\left(\alpha-\mathrm{Al}_{2} \mathrm{O}_{3}\right.$ on top of the bond coat). The temperature profile used in the cyclic oxidation tests is shown in Figure 11. 


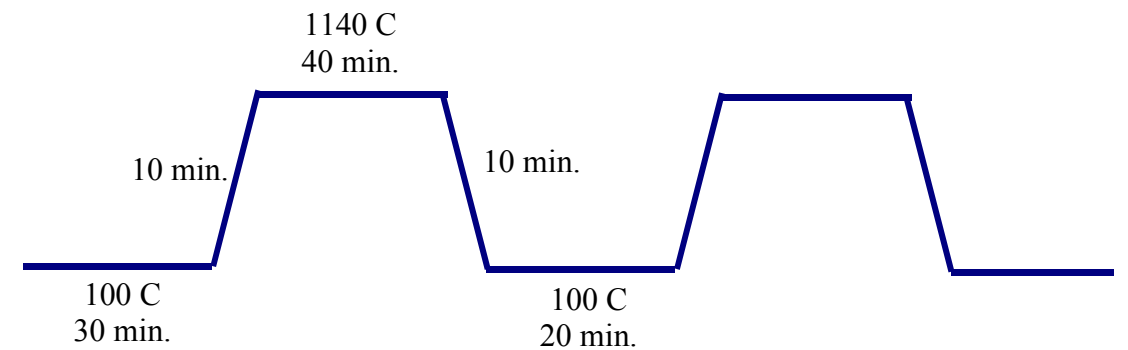

Figure 11. Thermal cycling profile used in our characterization studies. The actual temperature profile during the cooling stage was more concave, although the lowest temperature did reach $100^{\circ} \mathrm{C}$.

The weight change was measured on the cycled samples, and the results are tabulated in Table 3.

Table 3. Sample Weight Change with Cycles

\begin{tabular}{|c|c|c|c|}
\hline $\begin{array}{c}\text { Number of } \\
\text { Cycles }\end{array}$ & $\begin{array}{c}\text { Weight, Sample B } \\
\text { gram }\end{array}$ & $\begin{array}{c}\text { Weight, Sample C } \\
\text { gram }\end{array}$ & $\begin{array}{c}\text { Weight, Sample D } \\
\text { gram }\end{array}$ \\
\hline 0 & 5.0089 & 8.5091 & 14.1123 \\
\hline 25 & 5.0106 & 8.4901 & 14.1211 \\
\hline 50 & 5.0122 & 8.0448 & \\
\hline 75 & 5.0125 & & \\
\hline 100 & 5.0128 & & \\
\hline
\end{tabular}

$\mathrm{B}-\mathrm{NiCoCrAlY}+\mathrm{Al}_{2} \mathrm{O}_{3}$, both sides coated

C-NiCoCrAlY, both sides coated

D-Bare Sample

Among these, sample B was cycled up to 300 cycles before it showed significant weight loss. For this sample, weight change after 150 cycles was only $0.1085 \mathrm{mg} / \mathrm{cm}$. On the other hand, both samples $\mathrm{C}$ and $\mathrm{D}$ exhibited substantial weight loss, and visual observations showed that oxides had formed and spalled. Therefore, cycling was discontinued on samples C and D.

Figure 12 illustrates the weight change per unit area as a function of the number of thermal cycle.

Figures 13-15 show macrophotos of the samples after various oxidation cycles. Substantial oxidation was observed on the bare substrate (sample D) after only 25 thermal cycles. Oxidation and coating spallation (weight loss) was observed on sample $\mathrm{C}$ (bond coated) after 50 cycles. The surface of the $\alpha-\mathrm{Al}_{2} \mathrm{O}_{3}$ coated sample (sample B) remained pristine up to 150 thermal cycles, but thereafter it exhibited gradual roughness change likely associated with local TGO damage and minor spallation behavior. Testing was discontinued after 300 cycles because of lack of time. Overall, these results clearly demonstrate the effectiveness of the $\alpha$ $\mathrm{Al}_{2} \mathrm{O}_{3}$ layer in retarding the oxidation of the bond coat. 


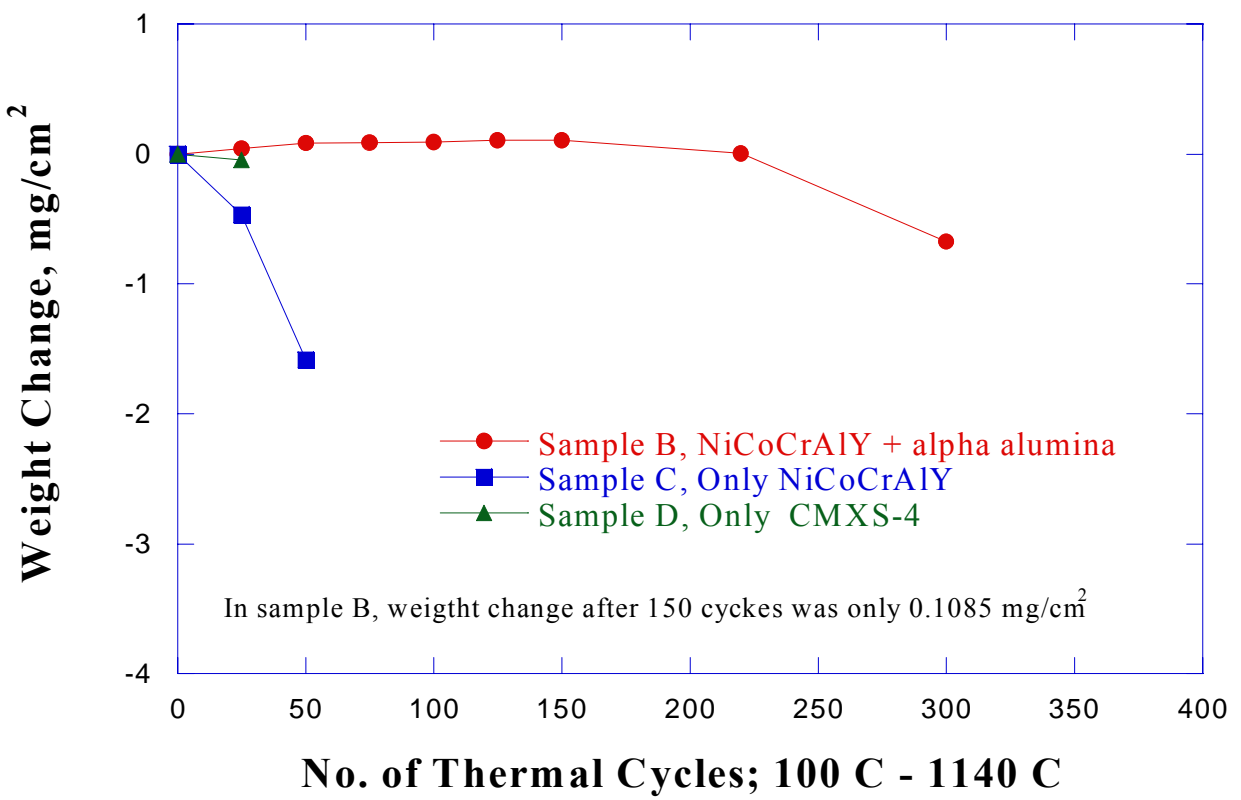

Figure 12. Comparison of weight change data for the three indicated samples.

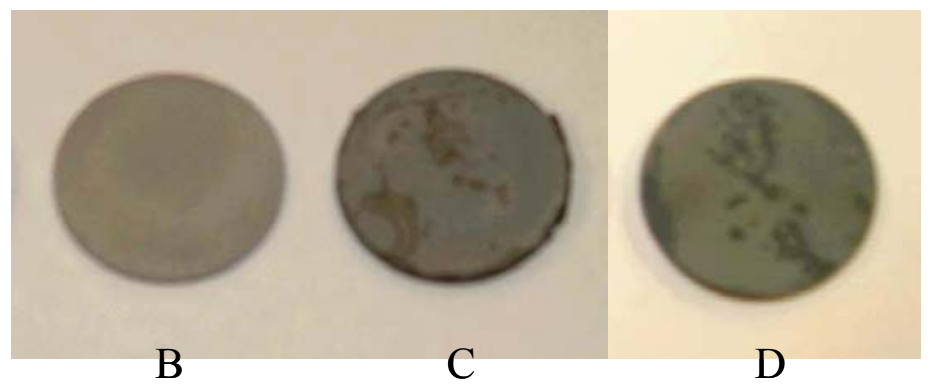

Figure 13. Macrophoto of samples $\mathrm{B}\left(\mathrm{CMSX}-4+\mathrm{NiCoCrAlY}+\alpha-\mathrm{Al}_{2} \mathrm{O}_{3}\right), \mathrm{C}(\mathrm{CMSX}-4+$ $\mathrm{NiCoCrAlY})$ and D (bare CMSX-4) after 25 cycles $\left(100^{\circ} \mathrm{C}-1140^{\circ} \mathrm{C}\right)$.

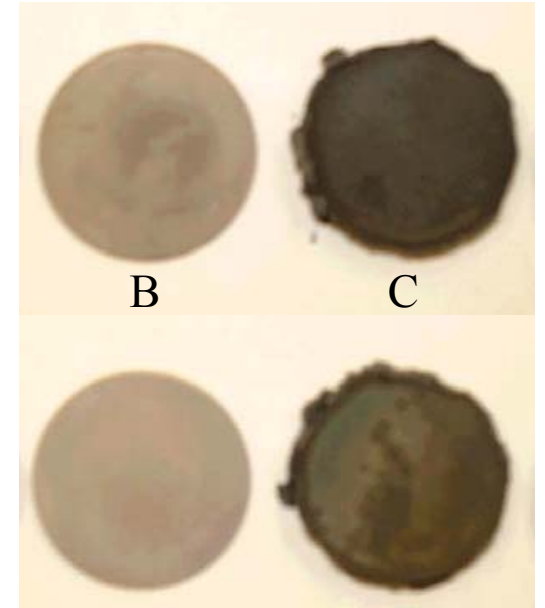

Figure 14. Macrophotos of samples B and C after 50 cycles. Both sides of the samples are illustrated here. 


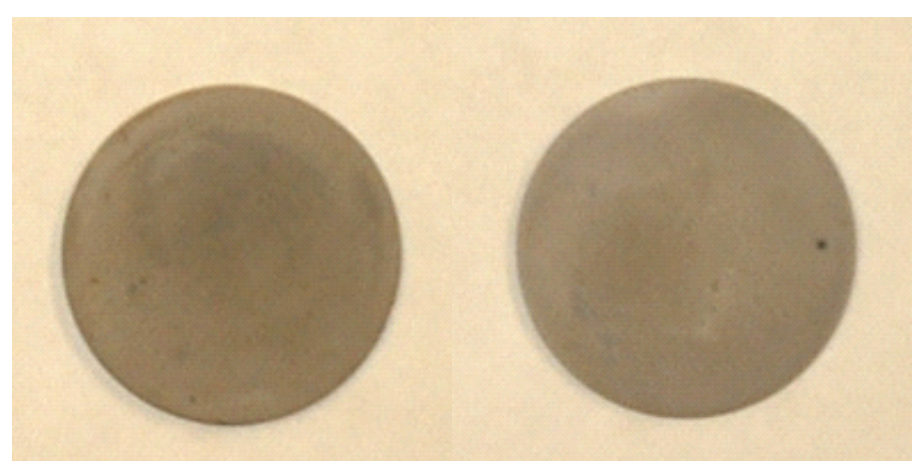

Figure 15. Both faces of sample B (CMSX-4 $\left.+\mathrm{NiCoCrAlY}+\alpha-\mathrm{Al}_{2} \mathrm{O}_{3}\right)$ after 150 cycles.

Figure 16 shows the cross section of sample B that experienced 300 cycles in the temperature range $100^{\circ} \mathrm{C}$ to $1140^{\circ} \mathrm{C}$. The micrograph shows the oxide layer in regions where spallation had not occurred. The accompanying elemental analysis indicates that the oxide is still largely alumina. Note that one trace does not reveal any $\mathrm{Ni}$, and the other spot shows some $\mathrm{Ni}$, but the elemental analysis is done such that electrons are also excited from the bondcoat. The grain size of the alumina is of the order of 0.5 micrometer.

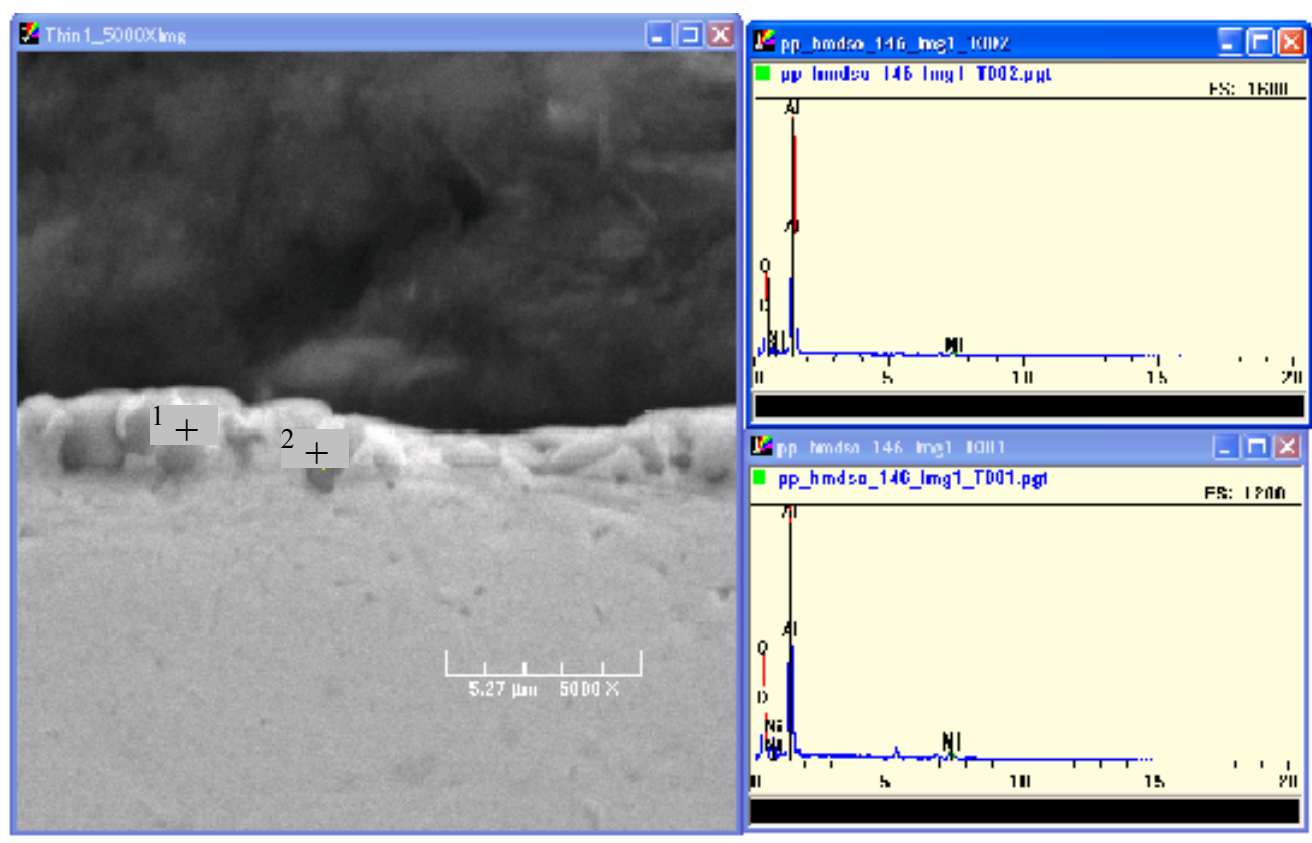

Figure 16. SEM micrograph of sectioned and polished sample B (without YSZ), that experienced 300 cycles in the range $100^{\circ} \mathrm{C}$ to $1140^{\circ} \mathrm{C}$.

Figure 17 is taken from another region of the same sample, and once again illustrates that the oxide layer is nearly pure alumina. In this case partial delamination of the oxide from the bondcoat may be observed. From the oxide thickness it is clear that the alumina layer had grown, but we are unable to distinguish between the deposited alpha alumina and the TGO. The alumina layer here appears to have a columnar morphology. However, much more analysis (both SEM and XRD-tecture) need to be done to confirm any texture in the alumina layer. 


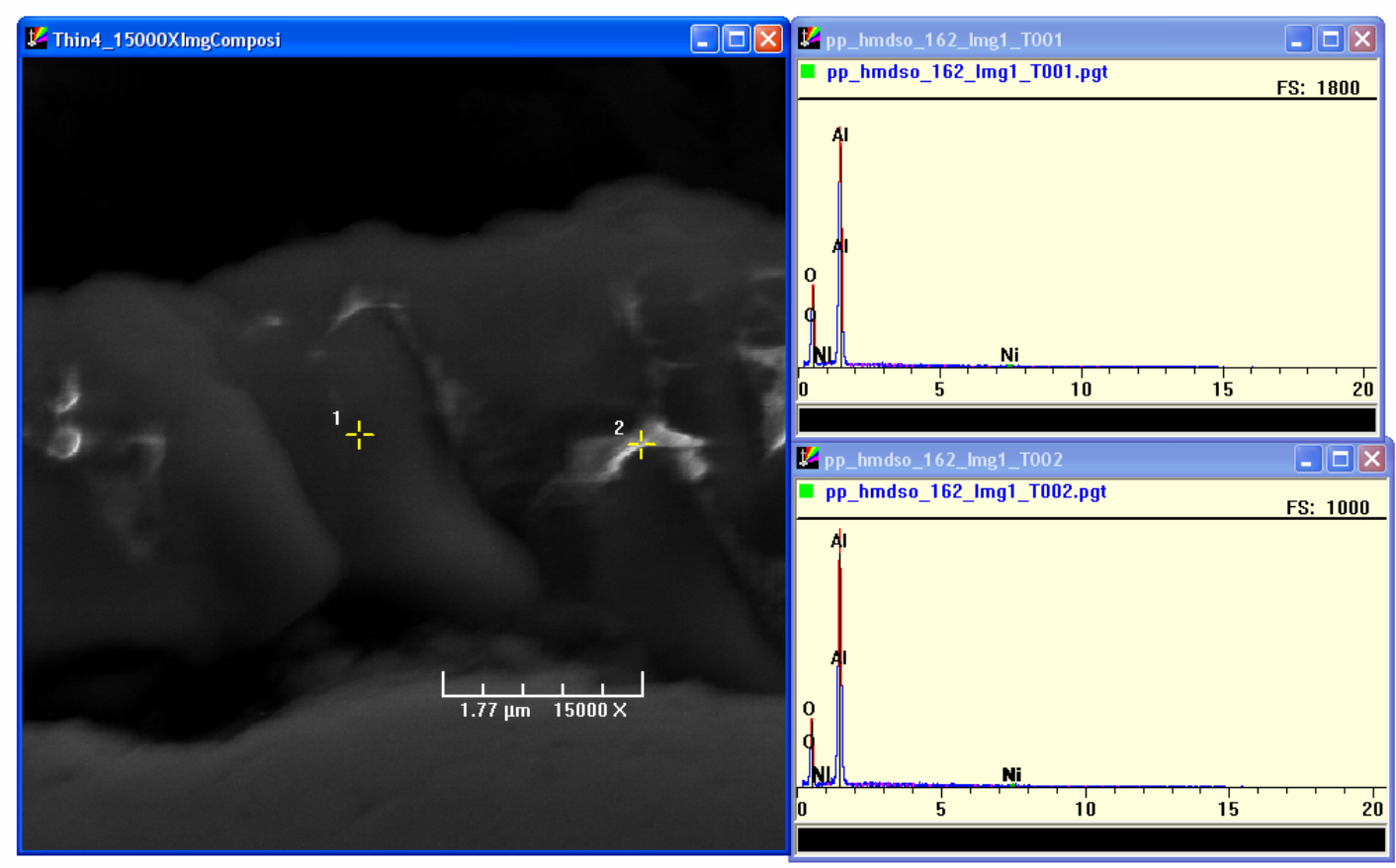

Figure 17. Another region of sample B (without YSZ) showing the oxide layer after thermal cycling. The oxide layer is pure alumina, as may be observed from the elemental analysis shown on the right.

\section{$\underline{\text { YAG/Bond Coat }}$}

YAG coating was deposited on top of the bond coat by arc enhanced sputtering technique. YAG sputter target was prepared by sintering YAG powders. YAG coating was deposited on top of the bond coated substrate at room temperature. The YAG coating thickness was $\sim 1.5$ micron. The as-deposited YAG coating was found to be amorphous according to XRD. The as-deposited coating was post annealed at $1100^{\circ} \mathrm{C}$. The XRD pattern of the annealed sample indicated the formation of YAG phase. Figure 18 represents the XRD pattern of the YAG coated bond coat exhibiting few peaks corresponding to YAG phase. The rest of the peaks in the XRD pattern belong to that of the bond coat. This observation indicates that the used deposition technique is capable of producing YAG phase.

\section{$\underline{\text { Bond Coat } / \alpha-\mathrm{Al}_{2}} \underline{\mathrm{O}}_{3} /$ YSS}

Standard YSZ coating was deposited on some of the bond coat $/ \alpha-\mathrm{Al}_{2} \mathrm{O}_{3}$ coated sample. YSZ deposition was done at Howmet Corp. utilizing EBPVD technique. The YSZ coating thickness was $\sim 180-200 \mu \mathrm{m}$. Figure 20 shows a macrophotograph of YSZ coated samples having bond coat $/ \alpha-\mathrm{Al}_{2} \mathrm{O}_{3}$ on a CMSX-4 substrate. No visible defects were observed on the YSZ coating surface. Figure 19 represents a cross-sectional (X-SEM) micrograph of an as-deposited sample. All the three layers namely, (1) bond coat, (2) $\alpha-\mathrm{Al}_{2} \mathrm{O}_{3}$, and (3) YSZ are clearly visible. $\alpha-\mathrm{Al}_{2} \mathrm{O}_{3}$ coating thickness was estimated to be roughly $\sim 1.5 \mu \mathrm{m}$. Energy dispersive x-ray spectra (EDS) from each of the three layers viz. bond coat, $\alpha-\mathrm{Al}_{2} \mathrm{O}_{3}$ and $\mathrm{YSZ}$ are also shown respectively in Figure 20. Peaks of expected elements are clearly visible in the EDS spectra of each layer. 


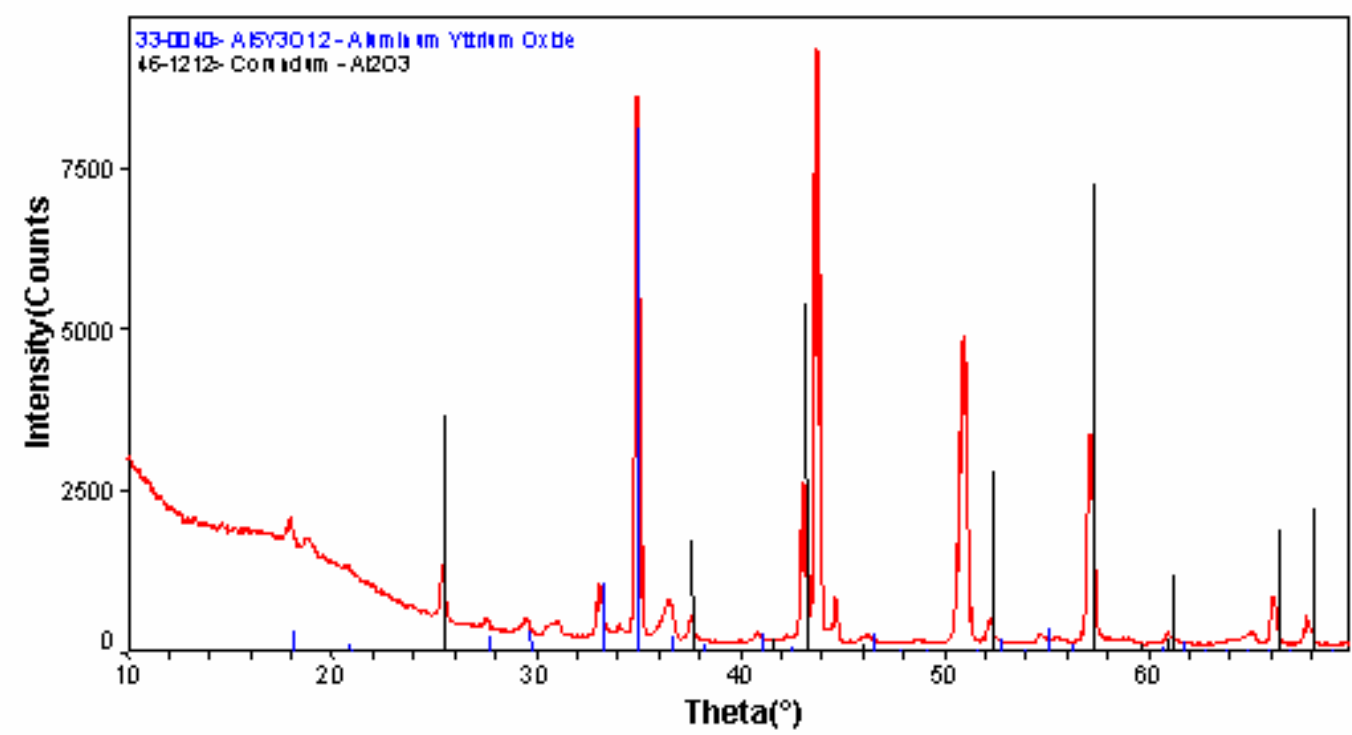

Figure 18. XRD pattern of YAG deposited on NiCoCrAlY substrate by magnetron sputtering at room temperature followed by post annealing at $1100^{\circ} \mathrm{C}$.

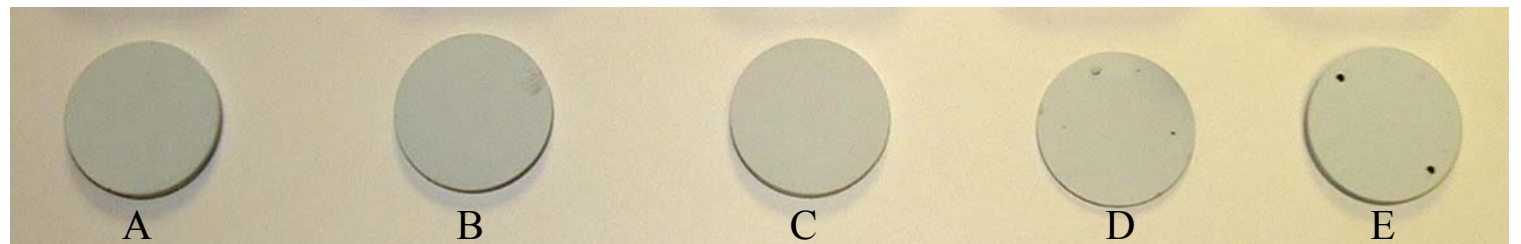

Figure 19. Macro photograph showing various specimens with the EB PVD YSZ coating having $\alpha-\mathrm{Al}_{2} \mathrm{O}_{3}$ on top of the bond coat (PtAl). The sample on the far right (sample F) is a standard PtAl-YSZ TBC system without $\alpha-\mathrm{Al}_{2} \mathrm{O}_{3}$ on top of the bond coat (PtAl).

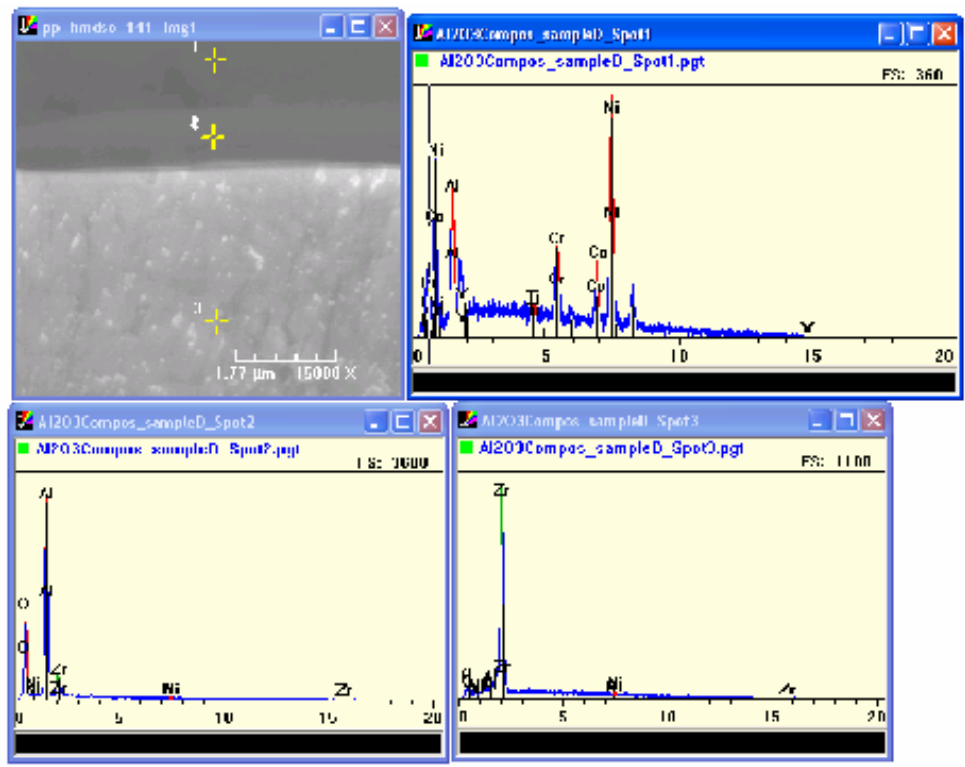

Figure 20. X-SEM Micrograph of As-deposited Bond Coat $/ \alpha-\mathrm{Al}_{2} \mathrm{O}_{3} / \mathrm{YSZ}$ and EDS Spectra of each layer. 
Thermal cycling tests on YSZ coated TBC samples were also conducted. The temperature cycle was similar to the YSZ-free samples (see earlier Figure 10), except that the maximum temperature was different. The test results are provided in Table 4.

Table 4. Thermal Cycling Test Data on YSZ Coated Samples

\begin{tabular}{|c|c|c|c|}
\hline Sample No. & Description & Cycles & Comments \\
\hline $\mathrm{A}$ & $\begin{array}{l}\text { NiCoCrAlY+alpha } \\
\text { alumina+YSZ }\end{array}$ & $\begin{array}{l}150\left(100^{\circ} \mathrm{C}-1140^{\circ} \mathrm{C}\right)+ \\
100\left(\text { at } 100^{\circ} \mathrm{C}-1230^{\circ} \mathrm{C}\right)\end{array}$ & $\begin{array}{l}\text { No damage } \\
\text { TBC failure }\end{array}$ \\
\hline B & $\begin{array}{l}\text { NiCoCrAlY+alpha } \\
\text { alumina+YSZ }\end{array}$ & $\begin{array}{l}150\left(100^{\circ} \mathrm{C}-1140^{\circ} \mathrm{C}\right)+ \\
100\left(\text { at } 100^{\circ} \mathrm{C}-1230^{\circ} \mathrm{C}\right)\end{array}$ & $\begin{array}{l}\text { No damage } \\
\text { TBC failure }\end{array}$ \\
\hline $\mathrm{C}$ & $\begin{array}{l}\text { NiCoCrAlY+alpha } \\
\text { alumina+YSZ }\end{array}$ & $\begin{array}{l}150\left(100^{\circ} \mathrm{C}-1160^{\circ} \mathrm{C}\right)+ \\
100\left(100^{\circ} \mathrm{C}-1160^{\circ} \mathrm{C}\right)\end{array}$ & $\begin{array}{l}\text { No Damage } \\
\text { Partial TBC failure }\end{array}$ \\
\hline $\mathrm{D}$ & $\begin{array}{l}\text { NiCoCrAlY+alpha } \\
\text { alumina+YSZ }\end{array}$ & Untested & $\begin{array}{l}\text { Used for } \\
\text { microstructural } \\
\text { examination }\end{array}$ \\
\hline $\mathrm{F}$ & Standard Pt-Al + YSZ & 100 (at $100^{\circ} \mathrm{C}-1230^{\circ} \mathrm{C}$ ) & TBC failure \\
\hline
\end{tabular}

Note that there was an over-temperature in one of the tests, where the maximum temperature was inadvertently $1230^{\circ} \mathrm{C}$ because of the use of a wrong thermocouple (S-type instead of an R-type). Nevertheless, sample $\mathrm{C}$ did experience the designated temperature range, and exhibited a life of approximately 250 cycles in the temperature range $100^{\circ} \mathrm{C}$ to $1160^{\circ} \mathrm{C}$. The maximum temperature for this sample was increased from $1140^{\circ} \mathrm{C}$, in order to reduce $\mathrm{TBC}$ life, to fit within the short Phase I program.

Our data may be compared with TBC data reported in the literature. Pt-Al based systems typically exhibit life of about 200 cycles in the temperature range $200^{\circ} \mathrm{C}-1177^{\circ} \mathrm{C}$ [13]. While this temperature range is larger than our case, the numbers suggest that our data are comparable to the best Pt-Al based systems in the market. Note that sample F (Pt-Al) in our faulty run also exhibited TBC failure, along with two of our alumina coated samples (A and B). However, because of the excessive temperature, with possible sintering of the YSZ, this data may not be of high significance. The life of Pt-Al based system was quoted as approximately 1050 cycles for a maximum temperature of $1135^{\circ} \mathrm{C}$ [14]. The lowest temperature is not mentioned in the article, but forced air cooling was used, and we estimate that to result in temperatures between 100 and $200^{\circ} \mathrm{C}$. We can attempt to compare our sample $\mathrm{C}$ data with this value by considering diffusion data for oxygen through alpha alumina with an activation energy of about $640 \mathrm{~kJ} / \mathrm{mole}$ [11]. If we use this approach, we estimate a cyclic life of about 650 cycles at $1135^{\circ} \mathrm{C}$, based on our 250 cycles at $1160^{\circ} \mathrm{C}$. Thus, our data are comparable with the best Pt-Al based TBC coatings.

Our data may also be compared with data on MCrAlY based system. Sohn et al. [15] conducted test on a Ni-20Co-20Cr-8Al-0.5Y (wt.\%) system on an IN 738 cast superalloy. The YSZ was deposited using standard EB PVD approach, and the authors report that the asdeposited coatings had an initial TGO layer (approx. $1 \mu \mathrm{m}$ ) formed during YSZ deposition. Samples were cycled up to $1121^{\circ} \mathrm{C}$ followed by forced air cooling. A 40 minute hold was used at $1121^{\circ} \mathrm{C}$. The average life of the TBCs was approximately 425 cycles. If we extrapolate our 1160 data again using the activation energy for oxygen diffusion in alpha alumina, the life of our samples at $1121^{\circ} \mathrm{C}$ is estimated to be 1125 cycles. Thus, our samples appear to perform 
significantly better than standard MCrAlY based TBCs. Of course, we have data from one sample, and the time-temperature superposition may not be accurate. Therefore, our extrapolation must be considered only for the purpose of initial assessment. Clearly, significantly more work is needed on this system.

Figure 21 shows the cross section of a piece of the YSZ layer that had delaminated from YSZ sample $\mathrm{C}$ after 250 cycles in the range $100^{\circ} \mathrm{C}$ to $1160^{\circ} \mathrm{C}$. The bond coat side revealed that failure had occurred at the $\mathrm{TGO} /$ bond coat interface, as has been also reported in a number of other studies on TBC systems (both Pt-Al nd MCrAlY based). This figure confirms our original expectation that the alpha alumina layer should promote the formation of alpha alumina at the expense of any other oxide, by keeping the local partial pressure low.

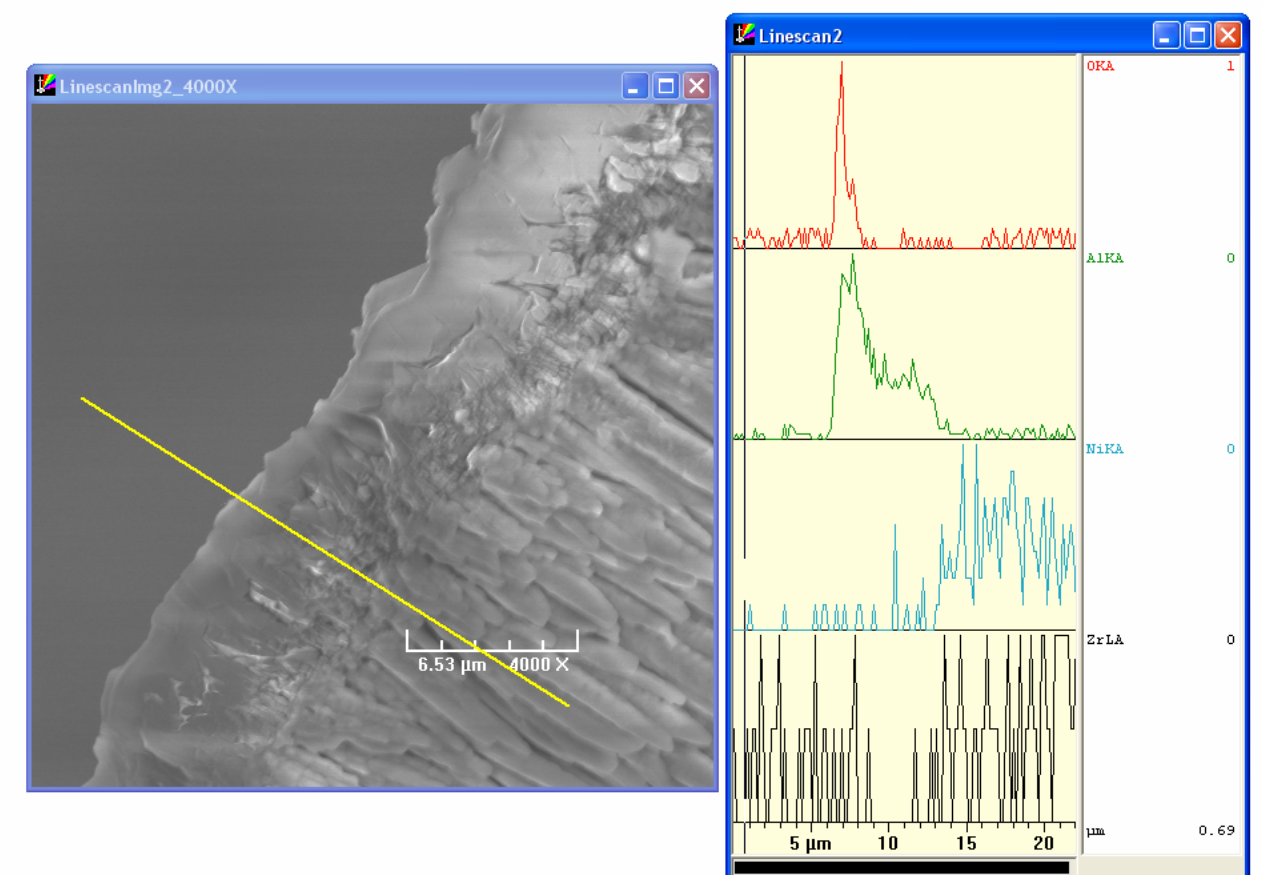

Figure 21. Cross section view of a YSZ piece that had delaminated from sample $\mathrm{C}$ after thermal cycling. The chemical trace is from the left to the right. The bondcoat side showed failure had occurred at the TGO/bond coat interface. More importantly, note that oxide layer is almost pure alumina, with no Ni. The presence of Ni on the YSZ side is surprising, and could have occurred during handling of the YSZ piece.

Figure 22 shows both surfaces of the YSZ chip that had delaminated from sample C after thermal cycling. The top side of the micrograph corresponds to the face that was in contact with the bondcoat. The bottom right shows the cross-section of the coating, with the columnar morphology of the YSZ clearly visible. The spot patterns correspond to numbers indicated in the micrograph, and confirm that at locations 2 and 3 , the composition is pure alumina.

Figure 23 shows the face of a delaminated YSZ chip from sample C. This face was in contact with the bondcoat prior to delamination, and represents the TGO. The analysis of the EDS pattern in provided in Table 5, and confirms the stoichiometry of the alumina phase. 


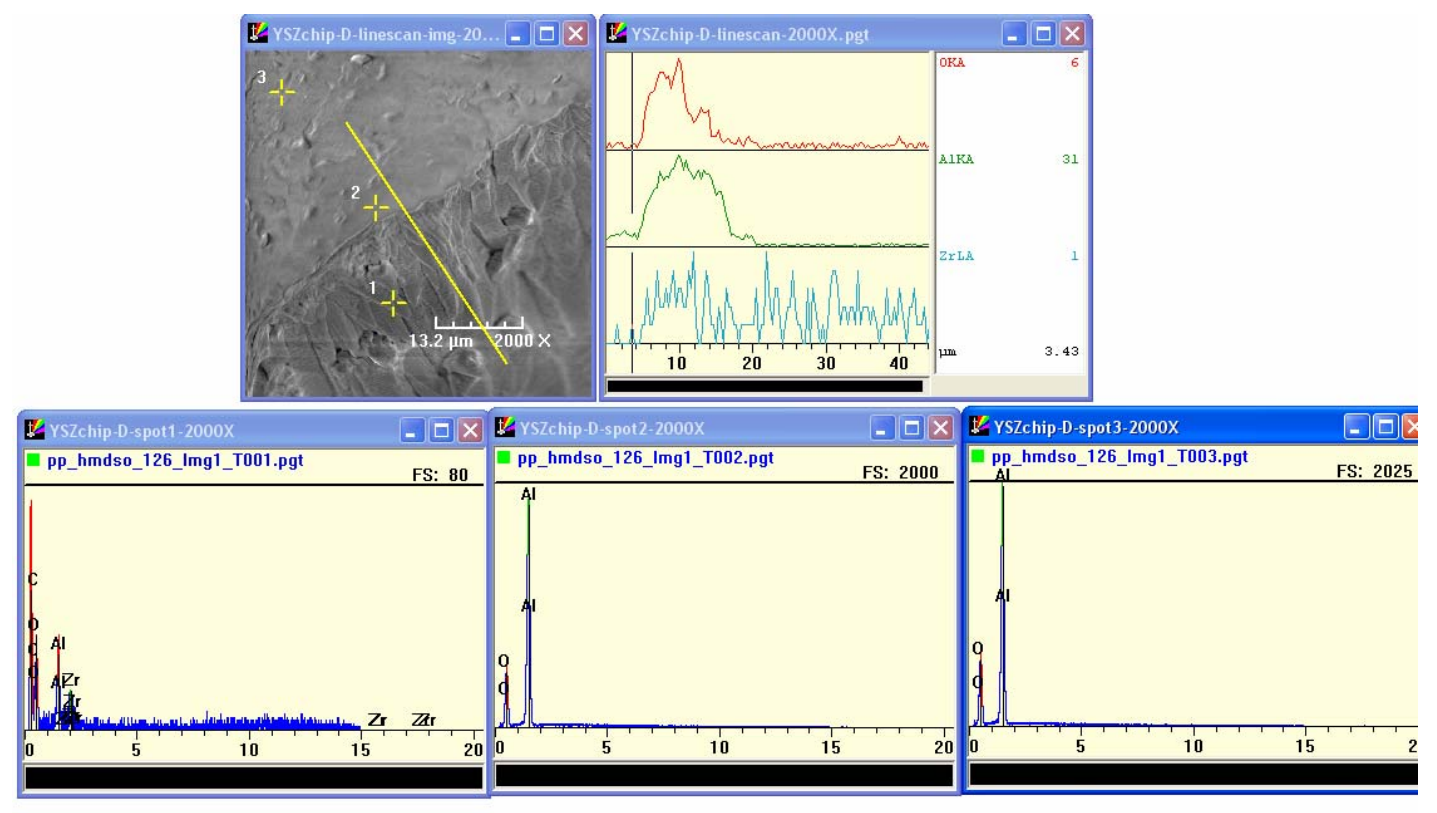

Figure 22. Micrograph showing two faces of a YSZ chip that delaminated from the bondcoat in sample $\mathrm{C}$ after thermal cycling. The elemental spot EDS patterns are also provided.

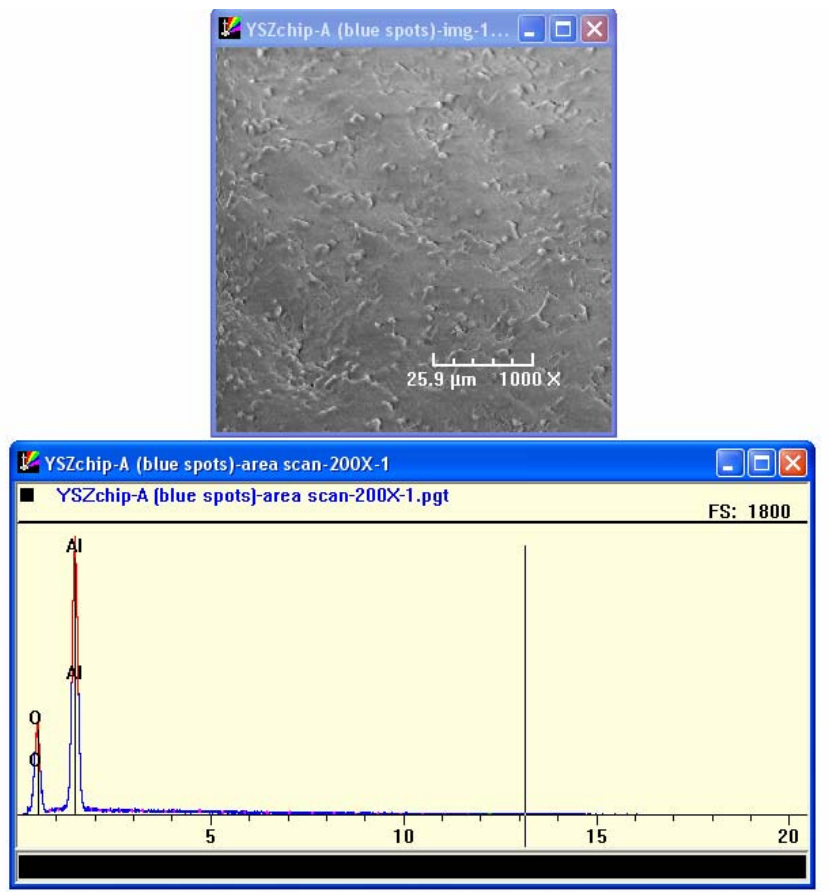

Figure 23. SEM Micrograph of the Delaminated YSZ Chip.

Table 5. Elemental Analysis of the Surface of a YSZ Chip that had Delaminated from Sample C after Thermal Cycling

\begin{tabular}{|c|c|c|c|c|c|c|}
\hline Element & Line & keV & KRatio & Wt\% & At\% & ChiSquared \\
\hline A1 & KA1 & 1.487 & 0.4113 & 53.47 & 40.54 & 39.64 \\
O & KA1 & 0.523 & 0.2412 & 46.53 & 59.46 & 14.49 \\
Total & & & & $\mathbf{1 0 0 . 0 0}$ & $\mathbf{1 0 0 . 0 0}$ & $\mathbf{2 5 . 4 0}$ \\
\hline
\end{tabular}


In summary, microstructures of the thermally cycled samples confirm the formation of only alumina in the TGO. Spinels such as $\mathrm{NiAl}_{2} \mathrm{O}_{4}$ appear to be absent. Although we have not conducted XRD of the TGO, we suspect that the alumina in the TGO must be alpha alumina, at these high temperatures. Overall, these results confirm our original contention that the alpha alumina layer will promote the formation of only slow growing alumina.

\section{Bond Coat/YAG/YSZ}

Standard YSZ coating was also deposited on bond coat/YAG coated sample. Again YSZ deposition was done at Howmet Corp. by EB PVD. The sample was cycled between room temperature and $1100^{\circ} \mathrm{C}$ for 100 cycles. The macrophotographs of the sample after 30 and 100 cycles are shown in Figures 24 (a,b). It is clear that the even after 100 cycles the surface looks pristine. Due to time constraint, more work on this sample was not possible in Phase I. However, this preliminary work does indicate the potential of YAG coating in enhancing the life of the TBC system.

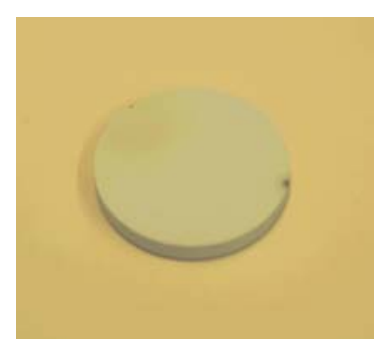

30 cys at $1100^{\circ} \mathrm{C}$

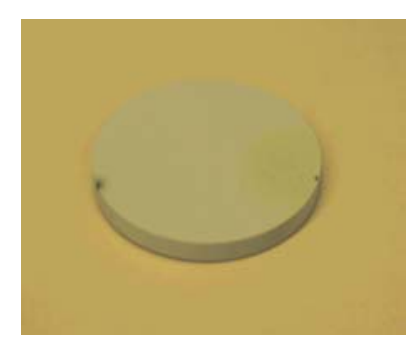

100 cys at $1100^{\circ} \mathrm{C}$

Figure $24(\mathrm{a}, \mathrm{b}) . \quad$ Macrophoto of Bond Coat/YAG/YSZ Sample After 30 and 100 Cycles $\left(100-1100^{\circ} \mathrm{C}\right)$.

In summary, the Phase I experiments indicate the following.

(1) We are able to deposit a highly adherent and defect-free NiCoCrAlY on the superalloy substrate using the filtered cathodic arc deposition technique.

(2) XRD data confirm that the deposited alumina layer is $\alpha-\mathrm{Al}_{2} \mathrm{O}_{3}$, with little, if any, evidence of other aluminum oxides.

(3) Thermal cycling tests indicate excellent integrity of the $\alpha-\mathrm{Al}_{2} \mathrm{O}_{3}$ sublayer under thermal cycling conditions $\left(100^{\circ} \mathrm{C}-1140^{\circ} \mathrm{C}\right.$, with a 40 minute hold at $\left.1140^{\circ} \mathrm{C}\right)$. Results are provided in the form of weight change measurements, macro photographs of thermally cycled samples, and SEM micrograph of a sample (without YSZ) after 300 ncycles $\left(100^{\circ} \mathrm{C}-1140^{\circ} \mathrm{C}\right)$. Previous experiments have shown that the alumina layer easily spalls if the deposited layer is not fully $\alpha-\mathrm{Al}_{2} \mathrm{O}_{3}$.

(4) Tests on the TBC system (CMSX-4 + NiCoCrAlY $\left.+\alpha-\mathrm{Al}_{2} \mathrm{O}_{3}\right)$ indicate good performance under thermal cycling. The performance is better than MCrAlY based TBC, and comparable with data on Pt-Al based system. These are major accomplishments considering the low $\mathrm{Al}$ content of the NiCoCrAlY, and the observation of only alumina formation in a MCrAlY based system. 


\subsection{SUMMARY OF PHASE I RESULTS}

The purpose of the Phase I project was to demonstrate the feasibility of the development of a TBC system design composed of NiCoCrAly bond coat on a single crystal CMSX-4 substrate with either $\alpha-\mathrm{Al}_{2} \mathrm{O}_{3}$ or YAG sublayer and an EB PVD YSZ top coat as thermal barrier layer. The approach was to deposit NiCoCrAlY and $\alpha-\mathrm{Al}_{2} \mathrm{O}_{3}$ or YAG utilizing UES' LAFAD system and YSZ by EB-PVD. The Phase I objective was met in that the highly smooth and dense bond coat (NiCoCrAlY) was developed by filtered arc technique. Also the development of $\alpha-\mathrm{Al}_{2} \mathrm{O}_{3}$ coating on top of bond coat was demonstrated and confirmed by XRD measurements in a reproducible manner. Moreover, YAG coating deposition on top of the bond coat was also demonstrated and the deposition conditions were identified. Also, in Phase I, isothermal and cyclic oxidation tests of coated materials (with/without the outer YSZ layer) were conducted and compared with the NiCoCrAlY based system without $\alpha-\mathrm{Al}_{2} \mathrm{O}_{3}$ or YAG sub layer. A superior performance of the TBC system with $\alpha-\mathrm{Al}_{2} \mathrm{O}_{3}$ (YAG) as sublayer was demonstrated. The accomplishments in Phase I can be summarized as follows:

1. Conditions were determined to deposit highly smooth and dense coating of NiCoCrAlY bond coat.

2. Conditions were found for reproducible deposition of $\alpha-\mathrm{Al}_{2} \mathrm{O}_{3}$ coating on the $\mathrm{NiCoCrAlY}$ bond coat. The deposition of $\alpha-\mathrm{Al}_{2} \mathrm{O}_{3}$ was confirmed by $\mathrm{x}$-ray diffraction.

3. Conditions were found for reproducible deposition of YAG coating on the NiCoCrAlY bond coat. The deposition of YAG was confirmed by X-ray diffraction technique.

4. Cyclic oxidation tests of the NiCoCrAlY bond coat with and without $\alpha-\mathrm{Al}_{2} \mathrm{O}_{3}$ sublayer were conducted.

5. During the oxidation tests weight gain of the coupons was monitored as a function of time.

6. Microstructure of the oxidized and the as-coated coupons were determined by optical and scanning electron microscopy (SEM).

7. Oxidation tests revealed that $\alpha-\mathrm{Al}_{2} \mathrm{O}_{3}$ coated bond coat coupons have better oxidation resistance and hence longer life compared to the bond coat without sub layers.

8. Cyclic oxidation test of YSZ coated coupons (bond coat on CMSX-4 substrate) with and without $\alpha-\mathrm{Al}_{2} \mathrm{O}_{3}$ or YAG sublayer was conducted.

9. Microstructure of the oxidized coupons (containing the alumina sublayer) was determined by a field emission SEM attached with a state-of-the-art X-ray microanalysis system. Those observations indicate that only aluminum oxide formed in the TGO, in preference to other oxides such as Ni rich spinel. This confirmed our original hypothesis that the alpha-alumina sublayer would promote growth of the stable and slower growing alpha alumina in the TGO in preference to other oxides. We believe this constitutes a major accomplishment of our project.

10. Oxidation tests revealed that YSZ coated coupons with YAG sublayer remained intact up to 100 cycles at $1100^{\circ} \mathrm{C}$. 
11. The cyclic oxidation tests on YSZ coated samples with the alpha-alumina sublayer indicate improved TBC life compared with MCrAlY based TBCs reported in the literature. Our data are, however, comparable to Pt-Al based TBC systems. This latter comparison should be considered in the context that our coating had not been optimized with regard to bondcoat composition (our NiCoCrAlY had much lower Al content than Pt-Al based systems), alpha-alumina thickness, or elemental additions that provide improved adhesion between the bondcoat and the TGO. Therefore, the at-par performance with PtAl based system should be considered a major accomplishment, particularly in view of our demonstration that TGO growth of our Al-poor NiCoCrAlY was only through alumina growth.

\section{REFERENCES}

1. T. E. Strangman, "Thermal Barrier Coatings for Airfoils", Thin Solid Films 127, 93 (1985), Ceramic TBC with alumina interlayer, US Patent No. 4880614 (1990).

2. J. T. Demasi et al. "TBC Life Prediction Model Development", P\&W, NASA C. R. 182230 (1989).

3. J. T. DeMasi-Marcin and D. K. Gupta, Surf. Coat. Tech., 68/69, 1 (1994).

4. R. V. Hillary et al., "Coatings for High Temperature Structural Materials" Trends and Opportunities", National Material Advisory Board Report, National Academy press Washington, DC (1996).

5. $\quad$ S.M. Metier and D.K. Gut, Trays ACME, 116, 250 (1994).

6. D. R. Clark and C. G. Levi, Annu. Rev. Mater. Res., 33, 383 (2003).

7. V.K. Tolpygo and D.R. Clarke, Surface rumpling of a (Ni,Pt) Al bond coat induced by cyclic oxidation, Acta Materialia, Vol. 48, (2000), pp. 3283-3293.

8. R. Bhattacharya and B.S. Majumdar, Improved Thermal Barrier Coating System Based on a Cathodically Deposited Alpha Alumina Sublayer, SBIR Phase I Report to the Air Force, Report No. UES P702, Funding No. F33615-00-C-5516 (April 2001).

9. Ian Wright, B. Pint, and R. Judkins, "Materials Research in Support of Industrial Gas Turbines," 1st Int. Conf. on Ind. Gas Turbine Technologies, CAME-GT, Brussels, 10-11 July 2003.

10. Y.F. Su, L.F. Allard, D.W. Coffey, and W.Y. Lee, Effects of an $\alpha-\mathrm{Al}_{2} \mathrm{O}_{3}$ thin film on the oxidation behavior of a single crystal Ni based superalloy, Metallurgical Transactions A, Vol. 35A, (2004), pp. 1055-1065.

11. M. Le Gall, A. M. Huntz, B. Lesage, C. Monty, and J. Bernardini, J. Mat. Sci., $\underline{30}$, pp. 201-211 (1995).

12. T. A. Parthasarathy, T. Mah and K. Keller, "Creep Mechanism of Polycrystalline Yttrium aluminum Garnet”, J. Amr. Ceram. Soc., 75(7), 1756 (1992).

13. Golam, Newaz, "Effect of Damage Processing on Spallation Life in Thermal Barrier Coatings," AFOSR Report, Nov. 9, 2001.

14. J.F. Schilbe, et al., Surf. \& Coat. Technol., 133-134, 35-59 (2000).

15. Y.H. Sohn, et al., Surf. \& Coat. Technol., 146-147, $70-78$ (2001). 